\title{
Mutator Suppression and Escape from Replication Error-Induced Extinction in Yeast
}

\author{
Alan J. Herr, Masanori Ogawa, Nicole A. Lawrence ${ }^{\text {aa }}$, Lindsey N. Williams, Julie M. Eggington, Mallika \\ Singh $^{\text {ab }}$, Robert A. Smith, Bradley D. Preston* \\ Department of Pathology, University of Washington, Seattle, Washington, United States of America
}

\begin{abstract}
Cells rely on a network of conserved pathways to govern DNA replication fidelity. Loss of polymerase proofreading or mismatch repair elevates spontaneous mutation and facilitates cellular adaptation. However, double mutants are inviable, suggesting that extreme mutation rates exceed an error threshold. Here we combine alleles that affect DNA polymerase $\delta$ (Pol $\delta$ ) proofreading and mismatch repair to define the maximal error rate in haploid yeast and to characterize genetic suppressors of mutator phenotypes. We show that populations tolerate mutation rates 1,000-fold above wild-type levels but collapse when the rate exceeds $10^{-3}$ inactivating mutations per gene per cell division. Variants that escape this errorinduced extinction (eex) rapidly emerge from mutator clones. One-third of the escape mutants result from second-site changes in Pol $\delta$ that suppress the proofreading-deficient phenotype, while two-thirds are extragenic. The structural locations of the Pol $\delta$ changes suggest multiple antimutator mechanisms. Our studies reveal the transient nature of eukaryotic mutators and show that mutator phenotypes are readily suppressed by genetic adaptation. This has implications for the role of mutator phenotypes in cancer.
\end{abstract} Citation: Herr AJ, Ogawa M, Lawrence NA, Williams LN, Eggington JM, et al. (2011) Mutator Suppression and Escape from Replication Error-Induced Extinction in
Yeast. PLoS Genet 7(10): e1002282. doi:10.1371/journal.pgen.1002282

Editor: Gregory P. Copenhaver, The University of North Carolina at Chapel Hill, United States of America

Received April 21, 2011; Accepted July 21, 2011; Published October 6, 2011

Copyright: (c) 2011 Herr et al. This is an open-access article distributed under the terms of the Creative Commons Attribution License, which permits unrestricted use, distribution, and reproduction in any medium, provided the original author and source are credited.

Funding: This work was supported by the National Institutes of Health (R01 ES09927, R01 CA098243, R01 CA111582, P20 CA103728, and P01 AG01751) and the National Institute of Environmental Health Sciences-sponsored Center for Ecogenetics and Environmental Health at the University of Washington (P30 ES07033). LNW was supported by a Public Health Service, National Research Service Award (T32 GM07270). AJH holds a Hitchings-Elion Fellowship from the Burroughs Wellcome Fund. MS was supported by a fellowship from the University of Utah Graduate School. These studies were initiated at the University of Utah. The funders had no role in study design, data collection and analysis, decision to publish, or preparation of the manuscript.

Competing Interests: The authors have declared that no competing interests exist.

* E-mail: E-mail: bradp@uw.edu

aa Current address: Abbott Laboratories, Abbott Park, Illinois, United States of America

ab Current address: Genentech, South San Francisco, California, United States of America

\section{Introduction}

Accurate DNA replication ensures the faithful transmission of genetic information between mother and daughter cells. To accomplish this important task, organisms have evolved a network of conserved pathways that govern DNA replication fidelity (reviewed in [1]). Polymerase proofreading and postreplication mismatch repair (MMR) are key determinants of fidelity, functioning to correct errors introduced by DNA polymerases during cell division (reviewed in [2-4]). Defects in these and other DNA repair pathways produce mutator phenotypes, which are characterized by increased rates of spontaneous mutation.

Mutator phenotypes arise spontaneously in nature and have mixed biological consequences (reviewed in [5-10]). In Escherichia coli and other bacteria, changing environmental conditions favor high mutation rates, which increase the likelihood of genetic adaptation [11-16]. However, after adaptation, mutator bacteria progressively lose fitness as they accumulate deleterious mutations in other genes $[14,17]$, and clones with lower mutation rates can evolve from mutator populations [14,16,18-20]. Thus, mutation rates in $E$. coli rise and fall as populations cycle through periods of adaptive and non-adaptive growth.

Mutators also impact eukaryotes. In mammals, mutator phenotypes fuel oncogenesis by providing the genetic diversity necessary for emergence of malignant clones [21,22]. Many sporadic human tumors show signs of an elevated mutation rate [23], and inherited defects in polymerase proofreading [24-26] or MMR (reviewed in $[27,28]$ ) confer mutator phenotypes and increase cancer risk. In the budding yeast Saccharomyces cerevisiae, loss of proofreading or MMR also elevates spontaneous mutation [29-34], and defective MMR can facilitate adaptation to changing environments [35,36].

Similar to bacteria, eukaryotic mutator alleles are detrimental in the long-term. Deleterious mutations accumulate faster in mutator compared to non-mutator yeast strains [37,38], and mutators eventually become extinct in a mutational meltdown process after serial passage through population bottlenecks [39]. This decline is accelerated in yeast with extreme mutation rates. Diploids that are homozygous defective for both proofreading and MMR grow slowly and have mutations rates that are elevated 10,000-times above wild-type levels [40-42]. Double-mutant spores germinate but arrest at various cell-cycle stages after 6-7 mitotic divisions [40], suggesting that the accumulation of DNA replication errors drives the extinction of haploid mutator strains.

Here, we experimentally define the threshold of error-induced extinction in haploid $S$. cerevisiae and show that cells readily escape extinction via genetic suppression. These escape mutants emerge rapidly and carry second-site mutations that suppress the mutator 


\section{Author Summary}

Organisms strike a balance between genetic continuity and change. Most cells are well adapted to their niches and therefore invest heavily in mechanisms that maintain accurate DNA replication. When cell populations are confronted with changing environmental conditions, "mutator" clones with high mutation rates emerge and readily adapt to the new conditions by rapidly acquiring beneficial mutations. However, deleterious mutations also accumulate, raising the question: what level of mutational burden can cell populations sustain before collapsing? Here we experimentally determine the maximal mutation rate in haploid yeast. We observe that yeast can withstand a 1,000-fold increase in mutation rate without losing colony forming capacity. Yet no strains survive a 10,000 fold increase in mutation rate. Escape mutants with an "anti-mutator" phenotype frequently emerge from cell populations undergoing this error-induced extinction. The diversity of antimutator changes suggests that strong mutator phenotypes in nature may be inherently transient, ensuring that rapid adaptation is followed by genetic attenuation which preserves the beneficial, adaptive mutations. These observations are relevant to microbial populations during infection as well as the somatic evolution of cancer cells.

phenotype. Our findings show that mutators are intrinsically unstable and that spontaneous suppressors moderate high mutation rates in yeast.

\section{Results}

\section{Abrupt Loss in Viability with Increased Mutation Rate}

To obtain a range of mutator strains suitable for defining the maximal mutation rate in yeast, we conducted a mutagenesis screen of the POL3 gene, which encodes the catalytic subunit of DNA polymerase $\delta(\mathrm{Pol} \delta)$. We used a plasmid shuffling strategy $[29,43]$ to introduce mutated pol3 alleles into strains proficient (MSH6) or deficient (msh64) for MMR (Figure S1). The screen focused on conserved residues in the proofreading exonuclease domain of Pol $\delta[44,45]$ that, when mutated in msh6 cells, are expected to preferentially increase base-substitution and \pm 1 frameshift mutations [40,46-49].

Our analysis identified 21 amino acid substitutions in the Pol $\delta$ proofreading domain that individually conferred a range of increased spontaneous mutation frequencies (Figure S2). These alleles had no observable effect on colony formation in MSH6 cells. However, four alleles (pol3-01, pol3-F406A, pol3-D407A and pol3- $1516 F$ ) did not yield visible colonies when shuffled into msh64 cells. This result is consistent with previous reports of synthetic lethality between the proofreading-deficient pol3-01 allele and MMR-defective alleles pms14, msh24, or msh64 $[40,41,50]$.

To determine whether the loss of growth capacity correlated with mutator strength, we quantified the spontaneous mutation rates of a subset of pol3 alleles in the presence or absence of MSH6 (Figure 1A). Alleles that imparted a 2- to 8-fold increase in the mutation rate of MSH6 cells $(R 459 A, G 400 A$, Y 401A, D396A, Y410A, K491R and D463A) were compatible with survival when MSH6 was deleted. These pol3 msh64 double-mutants had mutation rates that were 15 - to 150 -times greater than the corresponding pol3 MSH6 strains, consistent with synergy between pol3 mutators and msh64. In contrast, pol3 alleles that increased the mutation rate 25- to 50-fold in MSH6 cells (D407A, pol3-01, $1516 F$ and F406A) conferred a loss of colony-forming capacity in $m s h 64$ cells $\left(<1\right.$ colony $/ 10^{5}$ cells plated; Figure 1B). Thus, the transition to no colony formation occurred over a narrow range of increasing mutation rates. This abrupt loss of growth capacity implies the existence of a threshold for errorinduced extinction.

\section{Mutants That Escape Error-Induced Extinction}

During our shuffling experiments, we observed occasional colonies that escaped pol3 msh64 synthetic lethality (Figure 2A). We speculated that second-site changes in Pol $\delta$ might rescue yeast from error-induced extinction by increasing DNA replication fidelity and thereby reducing the spontaneous mutation burden. To test this idea, we sequenced pol3 plasmids from error-induced extinction (eex) mutants that escaped synthetic lethality between msh64 and pol3-01, pol3-F406A or pol3-D407A. The plasmids retained the original pol3 mutator alleles, but also harbored additional second-site mutations in each pol3 sequence. Our initial experiment yielded three eex mutants encoding single amino-acid substitutions in Pol $\delta$ (E594G or W821C in pol3-01; T711P in pol3$D 407 A$ ) and two mutants with multiple substitutions (K689E, S725L and I1076V in pol3-F406A; R470C and T655A in pol3$D 407 A)$. Another mutation $(A 894 G)$ was found in a large-colony variant of pol3-D463A msh64 cells. When the second-site eex mutations were re-engineered into new plasmids together with their corresponding mutator alleles (pol3-01, pol3-F406A or pol3D407A), they rescued colony-forming capacity in msh64 cells and decreased the mutation rate of MSH6 cells 10- to 33-fold (Figure 2B). The eex mutations appeared to be functionally interchangeable; T711P (the pol3-D407A suppressor) also rescued pol3-01 msh64 lethality, and either T711P or E594G (a pol3-01 suppressor) restored normal growth to pol3-D463A msh64 cells. Considered together, these initial findings suggested that eex mutations within POL3 confer escape from error-induced extinction by exerting an antimutator phenotype.

To obtain a broader view of escape mechanisms, we performed a large-scale screen for mutants that suppress the synthetic lethality between pol3-01 and msh64 (Figure 2C). Mutants emerged from nearly every pol3-01 msh64 parent clone, and there was wide fluctuation in the number and size of mutant colonies, suggesting that escape variants arise randomly prior to selection on FOA. We isolated 113 independent eex mutants (Table S1). Seventy-four of these eex mutants carried pol3-01 plasmids that still conferred lethality in a fresh msh64 strain. We infer that these mutants harbor mutations in chromosomal genes that influence DNA replication fidelity. The remaining 39 eex mutants carried pol3-01 plasmids that did not cause synthetic lethality when isolated and independently re-shuffled into msh64 cells. DNA sequencing of these plasmids showed that, in addition to the pol301 allele, each plasmid contained a different secondary mutation in pol3. These secondary mutations encoded single amino-acid changes in Pol $\delta$ (Figure 3 and Figure 4) and rescued colonyforming capacity when engineered de novo into pol3-01 plasmids and shuffled into naïve msh64 cells. Consistent with our initial experiment, all of these intragenic eex mutations suppressed the pol3-01 mutator phenotype, as measured at two different genetic loci (Figure 2D and Table 1). The weakest eex alleles suppressed mutation rates three-fold, while the strongest suppressors lowered mutation rates to wild-type levels (Figure 2D). Thus, cells escape pol3-01 msh64 lethality by acquiring any one of a variety of second-site mutations that suppress the mutator effect of Pol $\delta$ proofreading deficiency. 


\section{Contributions of MMR and Proofreading to DNA Replication Fidelity In Vivo}

The eex mutants provided an opportunity to assess the proportion of Pol $\delta$ errors that are repaired by proofreading and MMR in vivo. Taking advantage of the viability of pol3-01,eex msh64 cells, we first compared the mutation rates of isogenic strains that lack Pol $\delta$ proofreading and differ only in their MMR activity. The average increase in mutation rate in pol3-01,eex strains after deletion of MSH6 was 157-fold (Table 1), consistent with Msh6-dependent repair of greater than 99\% of the errors generated by proofreading-deficient Pol $\delta$. As expected from the mutation biases conferred by pol3-01 or msh64 alone [40,46-48], spontaneous mutations in pol3-01,eex msh64 strains were almost exclusively base substitutions (Figure S3 and Table S2). Thus, our estimate primarily reflects the efficiency of base-base mismatch repair. This estimate is an average across multiple scoreable sites in $C A N 1$; MMR efficiencies at individual sites may vary widely [51].

To similarly estimate the efficiency of Pol $\delta$ proofreading in vivo, we initially determined the influence of eex alleles on mutation rates in the presence of proofreading. Most MMRproficient pol3-eex strains had no discernable mutator phenotype (Figure 2D, Table 2). However, in the absence of MSH6 many of the pol3-eex alleles produced slightly higher mutation rates than the POL3 msh64 control (Table 2). These alleles were excluded from our analysis, because their weak mutator phenotypes may result from altered partitioning or other defects that reduce proofreading efficiency [4,52]. Eight pol3-eex msh64 strains exhibited mutation rates within two-fold of POL3 msh64: G204D, H620Y, T711A, E594G, Y808C, W821C, H879Y, and $S 968 R$. The mutation rates of these pol3-eex msh64 strains were compared to rates of the corresponding pol3-01,eex msh64 cells. This strategy allowed us to examine isogenic strains that differ only in their Pol $\delta$ proofreading activity and lack the masking effects of Msh6-mediated MMR. Proofreading deficiency increased mutation rates an average of 163 -fold, indicating that the Pol $\delta$ exonuclease corrects greater than $99 \%$ of polymerase errors across the $C A N 1$ reporter gene. Assuming Pol $\delta$ proofreading and Msh6-dependent MMR act in series [40], we estimate their combined contribution to DNA replication fidelity in yeast at greater than $10^{4}$. Proofreading and MMR contribute similarly to replication fidelity in bacteria [53].

\section{Defining the Threshold of Error-Induced Extinction}

The pol3-01,eex MMR-proficient strains formed colonies with similar size and efficiency as the POL3 control (Figure 5A, left). Thus, the corresponding eex mutant polymerases must suffice for the essential functions of Pol $\delta$ in replication [54]. However, in the absence of MSH6, pol3-01,eex alleles with the strongest mutator phenotypes impaired growth (Figure 5A, center). We used these mutants, together with synthetic-lethal alleles, to estimate the maximal mutation rate compatible with haploid yeast proliferation.

The upper and lower limits of the maximal rate were determined as follows. First, we calculated the predicted mutation rates of $m s h 64$ strains harboring synthetically lethal pol3 alleles (pol3-01, pol3-F406A, pol3-D407A or pol3- $1516 F$ ) as the mutation rate of each pol3 MSH6 strain (Figure 1A) times 157 (the average increase in rate observed upon deletion of MSH6; see preceding section). These predicted rates ranged from $2 \times 10^{-3} \mathrm{Can}^{\mathrm{r}}$ mutants per cell division for pol3-01 msh64 and pol3-D407A msh64 to $4 \times 10^{-}$ ${ }^{3}$ for pol3-F406A msh64 (Figure 5B). Second, we determined the growth capacities of all mutator and suppressor strains in our collection using a semi-quantitative scale based on colony size.
Wild-type colony-forming capacity (+++) was consistently observed at rates as high as $5 \times 10^{-5}$ Can $^{\mathrm{r}}$ mutants per cell division (Figure 5B). As the mutation rate exceeded $5 \times 10^{-5}$, several strains exhibited a slow-growth phenotype $(++)$, and a single strain (pol3$01, H 8791$ msh64) showed a severe growth deficit $(+)$ at a mutation rate of $1 \times 10^{-3}$. These results demonstrate that the maximal mutation rate is reached when there are $\sim 10^{-3}$ inactivating mutations in CAN1 per cell division (Figure 5B). Rates exceeding this maximum result in a failure to form visible colonies (i.e., errorinduced extinction).

If the observed decline in viability is due to an error threshold, additional mutation stress should exacerbate the growth defect. We introduced pol3-01,eex alleles into msh24 cells, which are defective in both Msh6- and Msh3-mediated MMR and thus have $\operatorname{Can}^{\mathrm{r}}$ mutation rates that are 2- to 3-fold higher than msh64 cells $[3,41,47,48]$. Colonies were observed only in pol3-01 msh2 $\Delta$ strains with the strongest mutator suppressor alleles (Figure $5 \mathrm{~A}$, right). Collectively, these data suggest that pol3-01 msh64 cells with weak mutator suppressors are on the edge of error-induced extinction and that eliminating $\mathrm{MSH} 2$ increases mutation rates beyond an extinction threshold. Although pol3-01 msh24 strains with strong mutator suppressors formed distinct colonies, these colonies were generally smaller and less uniform than the POL3 $m s h 2 \Delta$ control. This variability in colony size suggests that viable pol3-01,eex msh2A cells quickly accumulate deleterious mutations that compromise replicative fitness. The observation that growth is impaired at mutation rates 10-times less than the $10^{-3}$ threshold (Figure 5B) suggests that accumulation of random mutations can impose a loss in fitness and shows that the growth capacity of haploid yeast declines even under conditions of nonlethal mutation burden.

\section{Discussion}

Mutators accelerate microbial adaptation and mammalian oncogenesis. However, the fitness cost of increased mutation imposes indirect selection pressure to reduce mutation rates. This counter-selection will occur after adaptation to a stable environment where conditions no longer favor the genetic potential of mutators. One possible mechanism to reduce mutation rates is the acquisition of compensatory alleles at modifier loci that suppress the mutator phenotype.

In this study, we took advantage of synergies between Pol $\delta$ proofreading and MMR to titrate yeast mutation rates up to lethal levels and study the fate of mutators under strong counterselection. We found that msh64 cells carrying hypomorphic proofreading alleles abruptly lose viability over a narrow range of increasing mutation rates (Figure 1). Thus, cell survival requires both proofreading and MMR to limit potentially lethal mutations introduced by Pol $\delta$. Mutant clones that escape this error-induced extinction arose spontaneously (Figure 2), frequently due to second-site changes in Pol $\delta$ (Figure 3 and Figure 4) that conferred antimutator phenotypes (Figure 2 and Table 1). Using our collection of mutator and antimutator strains, we found that the maximum mutation rate compatible with haploid yeast survival corresponds to $\sim 10^{-3}$ inactivating mutations in CAN1 per cell division (Figure 5). These studies provide evidence for an error threshold in yeast and demonstrate that genetic suppressors of error-prone replication spontaneously arise in eukaryotic mutator cells.

Below we consider error thresholds in relation to genetic complexity and mutational robustness, and we discuss potential mechanisms of mutator suppression. 


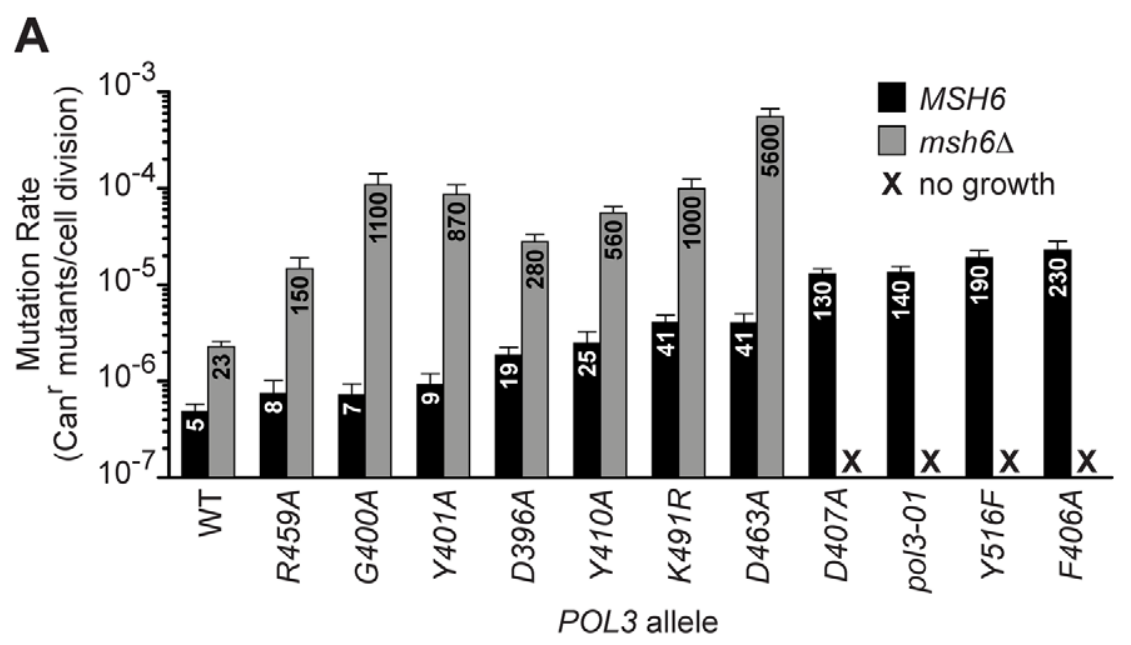

B

\begin{tabular}{|c|c|c|c|c|c|}
\hline & Wild Type & $G 400 A$ & $D 463 A$ & $D 407 A$ & po/3-01 \\
\hline MSH6 & a & 3) 流 & ( & 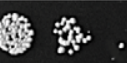 & s: \\
\hline & (-) 知 & W & 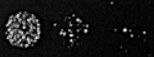 & & \\
\hline
\end{tabular}

Figure 1. Evidence for a threshold of error-induced extinction. A) Entry into error-induced extinction. Mutated pol3 alleles were introduced into haploid MSH6 and msh64 yeast by plasmid shuffling (Figure S1), and mutation rates were measured by fluctuation assays and calculated using the maximum likelihood method. Each bar represents the spontaneous mutation rate, expressed as canavanine-resistant (Can $\left.{ }^{r}\right)$ mutants per cell

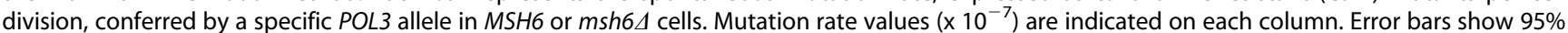
confidence intervals. WT, wild-type POL3; black, MSH6; gray, msh64; $\mathbf{X}$, no growth. B) Synthetic lethality of strong pol3 mutator alleles with msh64. Serial dilutions of haploid yeast containing POL3-URA3 and po/3-LEU2 plasmids were plated on SC FOA medium to select for cells that spontaneously lost POL3-URA3. Similar numbers of cells $\left(\sim 10^{5}, 10^{4}\right.$ and $\left.10^{3}\right)$ were plated for each set of alleles in the MSH6 and msh64 strains. Failed growth of msh64 cells carrying pol3-D407A or pol3-01 indicates synthetic lethality (right two panels). pol3-F406A and pol3-Y516F also failed to support colony formation in msh64 cells (not shown). Note the small size of pol3-D463A msh64 colonies.

doi:10.1371/journal.pgen.1002282.g001

\section{Error Thresholds, Genetic Complexity, and Mutational Robustness}

We observed loss of growth capacity when the CAN1 mutation rate exceeds $\sim 10^{-3}$ inactivating mutations per cell division (Figure 5). The yeast genome is comprised of $\sim 6000$ genes (http://www.yeastgenome.org). Thus, a mutation rate of $10^{-3}$ corresponds to the random inactivation of $\sim 6$ genes per cell per replication cycle (assuming CAN1 is typical). On average, one of these six mutations will involve a gene required for haploid cell viability $[55,56]$. Thus, there is a high probability that cells above the maximal mutation rate will acquire a lethal mutation after a few cell divisions. The restoration of cell growth via antimutator alleles (Figure 2) supports this hypothesis. Stalled DNA synthesis at nascent $3^{\prime}$ mispairs [57] and S-phase checkpoint signalling [58] could also contribute to growth arrest in strong mutators. However, it is not evident how MMR defects would exacerbate 3' mispair extension by $\mathrm{Pol} \delta$, and simultaneous loss of proofreading and MMR does not halt growth specifically in Sphase [40]. Rather, proofreading/MMR double mutants arrest with varied cell morphologies [40] that resemble those observed in a systematic promoter-repression screen of essential genes [59] (Figure S4). Considered together, the evidence suggests that random mutations in essential genes are a primary cause of errorinduced extinction. Synthetic cooperative interactions of nonlethal alleles will also contribute as cells accrue multiple mutations $[60,61]$. In a similar manner, bacteria exhibit a replication error threshold that correlates with the number of indispensable genes
[62], suggesting that maximal mutation rates can be used to estimate the genetic complexity of vital pathways in other organisms.

Error thresholds are also evident in diploids. Although diploid genomes generally buffer cells against the deleterious effects of mutation accumulation [63], haploinsufficient alleles still pose a significant threat to fitness. In a comprehensive library of diploid yeast heterozygotes, up to $20 \%$ of the hemizygous mutant strains exhibit reduced fitness during growth competition [64]. Observations of mutation meltdown in MMR-deficient cells [39] and lethality conferred by a hyper-mutator Pol $\delta$ variant [65] argue that diploid yeast are subject to an error threshold. The combined loss of Pol $\delta$ proofreading and MMR is also synthetically lethal in mice [25]. Similar to the situation in yeast [40], mouse cells defective for both proofreading and MMR are initially viable but arrest after a limited number of mitotic divisions [25]. This cessation of growth presumably results from an accumulation of mutations in genes required for cell propagation and embryo development.

Although cells eventually succumb to error-induced extinction, they tolerate substantial increases in mutation rate before losing viability. This mutational robustness is apparent in yeast, E. coli and mouse cells (Figure 6). We show that haploid yeast tolerate more than a 1,000-fold increase in mutation rate before exhibiting overt loss of colony-forming capacity (Figure 5B), and a comparable increase in mutation rate is required to cause catastrophic errors in E. coli [62], suggesting that prokaryotes and haploid eukaryotes share similar degrees of robustness toward 
A
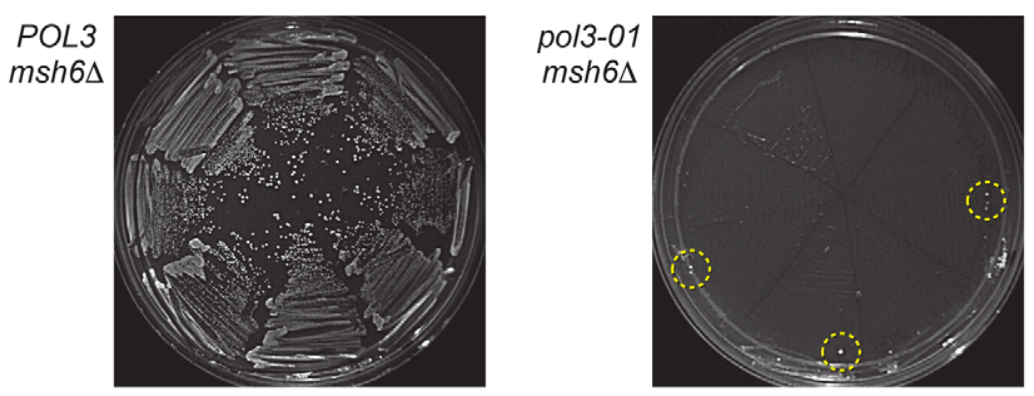

B

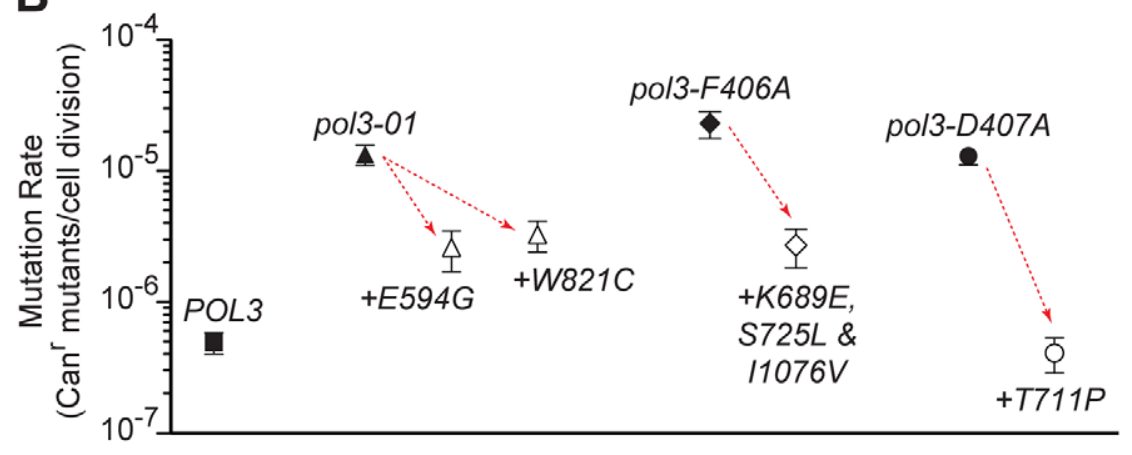

POL3 allele

C
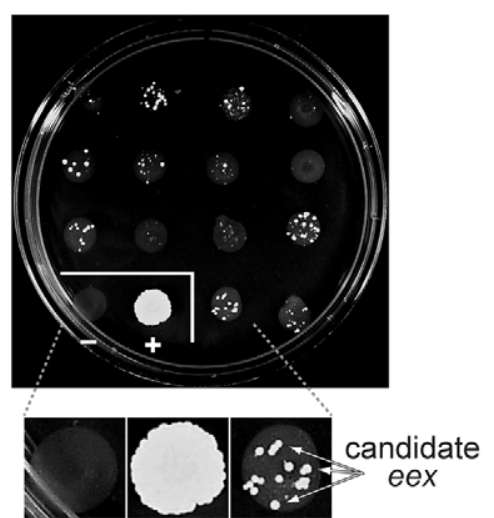

$\mathrm{plasmid}^{\mathrm{OL}^{3}} \mathrm{pol}^{3-0^{1}}$
D

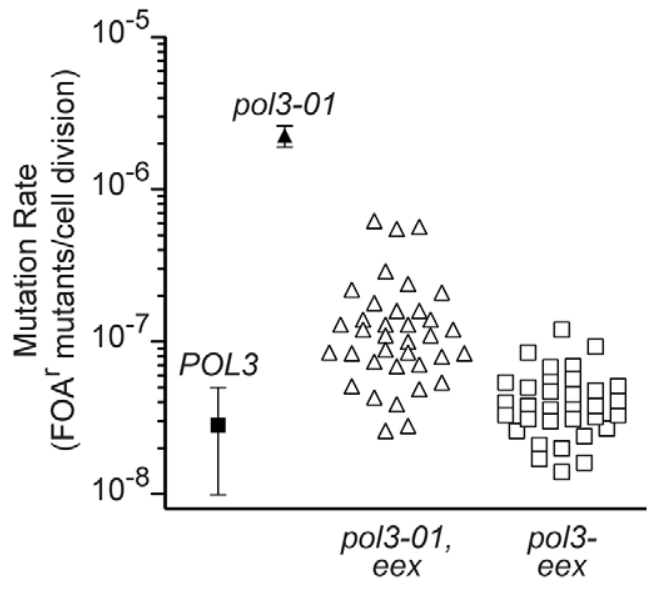

Figure 2. Escape from error-induced extinction. A) Emergence of colonies that escape pol3-01 msh6 4 synthetic lethality. Each segment of an FOA-containing SC plate (eight segments per plate) was streaked with an individual colony of POL3-LEU2 POL3-URA3 msh64 (left) or pol3-01-LEU2 POL3-URA3 msh64 (right) cells to select for loss of the POL3-URA3 plasmid (see Figure S1). Resultant POL3 msh64 cells formed abundant visible colonies (left), whereas pol3-01 msh6 cells did not (right). Colonies that escape pol3-01 msh64 synthetic lethality (eex mutants) arose at low frequency near the outer margins of the plate (circled) where cell densities were highest. Similar results were seen when po/3-F406A or po/3-D407A were shuffled into msh64 cells (not shown). B) Antimutator effects of eex alleles encoding second-site changes in Pol $\delta$. Rates of spontaneous mutation to canavanine-resistance ( $\mathrm{Can}^{\mathrm{r}}$ ) conferred by pol3-01, pol3-F406A or pol-D407A alone (filled symbols) and combined with intragenic eex alleles (open symbols) were determined in MSH6 cells. Downward arrows illustrate the reduction in mutation rates (i.e., the antimutator effect) caused by the second-site, amino-acid substitutions indicated beneath each datum point. Error bars show $95 \%$ confidence intervals. C) Representative plate from large-scale screen for eex mutants. Approximately $10^{6}$ cells from multiple independent pol3-01-LEU POL3-URA msh64 parent colonies were plated separately in $\sim 1-\mathrm{cm}$ spots on FOA-containing SC medium. LEU-only and POL3-LEU plasmids were also shuffled into msh6A cells as controls. FOA-resistant colonies arose at varied frequencies from each parent clone. Insert, magnified view showing colonies that are candidate eex mutants. plasmid, LEU-only plasmid with no POL3 gene. D) Mutation rates of eex mutants. Rates of spontaneous mutation to FOA-resistance (FOA ${ }^{r}$ ) were measured in a MMR-proficient strain with a chromosomal URA3 reporter gene. Each datum point represents a different $P O L 3$ allele. Mutation rates were determined from multiple independent fluctuation analyses of each allele. Confidence intervals (95\%) are shown for POL3 and pol3-01. Mutation rates and confidence intervals of individual eex alleles are in Table 1 and Table 2.

doi:10.1371/journal.pgen.1002282.g002 
T4 pol HSV1 pol T.g. pol B M.m. pol d

T4 pol

HSV1 pol

T.g. pol B

S.c. pol c

M.m. pol d

T4 pol

HSV1 pol

T.g. pol B

S.c. pol d

M.m. pol d

T4 pol

HSV1 pol

T.g. pol B

M.m. pol d

T4 pol

HSV1 pol

T.g. pol B

M.m. pol d

T4 pol
HSV1 pol

T.g. pol B

M.m. pol d

T4 pol

T4 pol

T.g. pol B

S.c. pol d

M.m. pol d

T4 pol HSV1 pol T.g. pol B M.m. pol d

T4 pol HSV1 pol T.g. pol B s.c. pol o M.m. pol d

T4 pol HSV1 pol T.g. pol B s.c. pol M.m. pol d

T4 pol

HSV1 pol T.g. pol B M.m. pol d

T4 pol HSV1 pol T.g. pol B M.m. pol d

(743) EESIRRILQ-EGEESVQEYYKNFEKEY--RQLDYKVIAEVKTA---NDIAKYDDKGWPGFKCPFHIRGVLTYRRAVSGLGVAPILDGNKVMVLPLREGNP (971) RALVDLLFYDDTVSGAAAALAERPAEEWLARPLPEGLQAFGAVLVDAHRRITDP-----ERDIQDFVLTAELSRHPR---AYTNKRLAHLTVYYKLMARRA (971) RALVDLLFYDDTVSGAAAALAERPAEEWLARPLPEGLQAFGAVLVDAHRRITDP-----ERDIQDFVLTAELSRHPR---AYTNKRLAHLTVYYKLMARRA
(624) ARVLEAILKHGDVEEAVRIVKEVTEKLSKYEVPPEKLVIYEQITR-DLKD-------YKATGPHVAVAKRLAARG-----IKIRPGTVISYIVLKGSGR
(851) NKVLKKILIERNVDGALAFVRETINDILHNRVDISKLIISKTL---AP--NY-------TNPQPHAVLAERMKRRE----GVGPNVGDRVDYVIIGGNDK (843) TSSLRRILVDRDPDGAVAHAKDVISDLLCNRIDISQLVITKELTRAAA--DY-------AGKQAHVELAERMKRRE----GVGPNVGDRVDYVIIGGNDK H879Y K891T Aं894V/G

T4 pol (837) F--GDKCIAWTPSGTELPKEIRSDVLSWIDHSTLFQKSFVKPLAGMCESAGMDYEEKASLDFLFG-----------------------------------HSV1 pol (1064) QVPSIKDRIP-----YVIVAQTREVEETVARLAALRELDAAAPGDEPAPPAALPSPAKRPRETPSPADPPGGÄSKPRKLLVSELAEDPAYAIA T.g. pol B (710) IGDRAIPFDEFDP--------AKHKYDAEYY IENQVLPAVERILRAFGYR------KEDLR------YQKTRQVGLGAWLKPKT---------S.c. pol d (935) L--YNRAEDP------LF--VLENN-IQVDSRYYLTNQLQNPIISIVAPI IGDKQANGMFVVKS---IKINTGSQKGGLMSF IKKVEACKSCKGPLRK-M.m. pol d (931) VAAYMKSEDP-----LF--VLEHS-LPIDTQYYLEQQLAKPLLRIFEPILGEGRAESVLLRGDHTRCKTVLTSKVGGLLAFTKRRNCCIGCRSVID---H

T4 pol (899)

HSV1 pol (1152) HGVALNTDYYFSHLLGAACVTFKALFGNNAKITESLLKRFIPEVWHPPDDVAARLRTAGFGAVGAGATAEETRRMLHRAFDTLA-

T.g. pol B (774)

s.c. pol d (1020) EGPLCSNCLARSGELYIKALYDVRDLEEKYSRLWTQCORCAGNLHSEVLCSNKNCDIFYMRVKVKKELQEKVEQLSKW-------

M.m. pol d (1020) QGAVCKFCQPRESELYQKEVSHLNALEERFSRLWTQCQRCQGSLHEDVICTSRDCPIFYMRKKVRKDLEDQERLLQRFGPPGPEAW 
Figure 3. Amino-acid changes in Pol $\delta$ eex mutants. Aligned sequences of five B-family DNA polymerases: Saccharomyces cerevisiae Pol $\delta$ (S.c. pol d), Mus musculus Pol $\delta$ (M.m. pol d), Thermococcus gorgonarius (T.g. pol B), bacteriophage T4 (T4 pol), and herpes simplex virus 1 (HSV1 pol). Secondary structural elements of yeast Pol $\delta$ [74] are indicated below the alignment and color coded to depict their domain locations (see Figure 4A): rectangles, $\alpha$-helices; arrows, $\beta$-strands; solid lines, loops; dotted lines, structure not solved. Conserved polymerase (Pol) and exonuclease (Exo) motifs are framed $[44,45,120]$. Amino-acid substitutions of interest in yeast Pol $\delta$ are placed underneath the alignment at the relevant positions, highlighted according to the following scheme: no highlight, po/3-01,eex mutations; green, po/3-D407A,eex mutations (R470C and T655A in one mutant, T711P in another); orange, pol3-F406A,eex mutations (three substitutions in the same mutant); blue, A894G mutation that rescued slow growth of pol3-D463A msh64 cells; yellow, pol3-01 (D321A,E323A); gray, pol3-t (D643N) and G447S (previously identified antimutator alleles; [121,122]). Residues that increase polymerase fidelity when mutated in T4 or HSV1 are indicated by aqua boxes in the alignment $[4,84-89,123]$. doi:10.1371/journal.pgen.1002282.g003

DNA polymerase errors. In comparison, diploid yeast and mouse cells retain replication capacity at mutation rates 10,000 -times higher than wild-type levels (Figure $6 ;[25,40,66])$. Thus, diploidy extends the threshold of error-induced cell death by five- to tenfold. These data suggest that cells can survive and persist during periods of high mutational loads. The maximal mutation rate will likely vary, depending on environmental conditions $[67,68]$, genetic redundancy $[63,69,70]$, the plasticity of genetic interactions $[71,72]$, and the ability of cells to buffer deleterious changes in essential proteins [73].

\section{Structural Implications of the eex Amino-Acid Substitutions}

We observed that escape mutants readily emerge when moderate mutators are pushed above the error threshold (Figure 2). One-third of the escape mutants resulted from second-site changes in Pol $\delta$ that suppress the proofreadingdeficient mutator phenotype. Recent structural studies of $S$. cerevisiae Pol $\delta[74]$ provide insight into potential mechanisms of mutator suppression by these intragenic eex alleles (Figure 4, Figures S5 and S6).

Many eex mutations alter amino acids around the polymerase active site that are predicted to influence dNTP binding or catalysis (Figure 4B). Effects may be mediated by direct interactions of mutated residues with the metal•dNTP substrate or via packing interactions that indirectly affect the substrate binding pocket. Other eex mutations map to a stretch of amino acids that bind the template near the active site and buttress the fingers domain, which contains residues that contour the template $\bullet$ NTP base pair (Figure S5). Amino-acid changes affecting active-site geometry, positioning of the template nucleotide, or stability of the catalytic conformation may act as antimutators by increasing selectivity for correct dNTPs or by slowing the rate of catalysis so that mispaired template primers have more time to dissociate from $\mathrm{Pol} \delta$. A model of dissociation and subsequent editing by an alternative enzyme [20,75] may best explain eex mutations that change amino acids along the DNA binding track (Figure 4C). Similarly, eex mutations in the exonuclease domain may impart structural changes that promote Pol $\delta$ dissociation during failed proofreading attempts (Figure S6). Intriguingly, two eex amino-acid substitutions (E642K and D643N) are located on the solvent-exposed surface of Pol $\delta$ (asterisk in Figure 4A), suggesting that changes in protein-protein interactions influence mutagenesis. Proteins encoded by eex loci extragenic to POL3 (Table S1) are candidate interacting partners.

Several alternative enzymes may function to edit Pol $\delta$ errors in the eex mutants. One candidate is proofreading by Pol $\varepsilon$. Yeast with deficiencies in both $\mathrm{Pol} \delta$ and Pol $\varepsilon$ proofreading exhibit a synergistic increase in mutation rate, suggesting one or both polymerases may proofread for the other [46]. Other candidates include the $3^{\prime} \rightarrow 5^{\prime}$ exonuclease activities of MRE11 [76] and Apn2 [77], or endonucleases such as $\operatorname{Rad} 1 / \operatorname{Rad} 10$ or Mus81/ Mms4 that cleave 3' flap structures during replication fork restart
[78-82]. An important consideration is that such alternative editing pathways may be redundant, with multiple activities masking the contributions of any one nuclease.

The locations of several eex substitutions in Pol $\delta$ resemble those of antimutators previously identified in bacteriophage T4 polymerase [4,83-86] and in herpes simplex virus polymerase [87-89], two B-family DNA polymerases similar to Pol $\delta$ (Figure 3). Genetic screens have also identified E. coli DNA polymerase I and III antimutator variants, and similar to our findings, these $E$. coli antimutators result from diverse amino-acid substitutions throughout the polymerase structures [19,20,90-92]. Some amino-acid substitutions in $\mathrm{T} 4 \mathrm{pol}$ are thought to increase polymerase fidelity by promoting 'hyper-editing' of the primer terminus by the integral proofreading exonuclease (reviewed in [4]). However, the eex mutations we describe mediate their antimutator effects without the aid of an active exonuclease domain, similar to previously isolated E. coli antimutators [19,20,90].

Taken together, this structural analysis suggests two general antimutator mechanisms for Pol $\delta$ eex mutations: 1) increased dNTP discrimination, thereby making Pol $\delta$ more accurate, and 2 ) increased dissociation from mispaired primer-templates, thereby allowing other enzymes to proofread Pol $\delta$ errors. eex mutations could also decrease errors at Okazaki fragment junctions by suppressing the strand-displacement activity of proofreadingdeficient Pol $\delta[52,93-95]$.

\section{Evidence for Other Pathways of Mutator Suppression}

Our study took advantage of synthetically lethal interactions between Pol $\delta$ proofreading and MMR alleles to select for antimutators. Several lines of evidence indicate that mutator suppressors also arise under non-lethal conditions and are not restricted to the Pol $\delta$ proofreading - MMR pathway. Morrison and Sugino observed mutator suppression in a yeast clone defective for Pol $\varepsilon$ proofreading and MMR [46], and an engineered second-site mutation in Pol $\varepsilon$ suppresses the mutator effect of Pol $\varepsilon$ proofreading deficiency [96]. In E. coli, suppressors of diverse mutator pathways (MMR, proofreading and DNA damage repair) emerge spontaneously in strains that are well below the error threshold [14,18-20]. In our studies, large-colony variants of slow-growing mutators were frequently observed (see, for example, Figure 5A), and in the one variant we pursued, we found the $A 894 G$ suppressor mutation. Collectively, these studies show that many defects in DNA replication fidelity can be genetically suppressed and suggest that both moderate and strong mutators are intrinsically unstable.

The facile emergence of mutator suppressors that we observed in yeast suggests that similar pathways of suppression exist in multicellular eukaryotes. This has implications for the role of mutator phenotypes in cancer [22,97]. During neoplastic transformation, mutator alleles that promote the formation of tumor cells are likely to incur a fitness cost due to an increase in mutational load. To offset this cost, suppressor alleles that reduce the mutation rate may emerge during the later stages of oncogenesis after genetic barriers to immortalization and metas- 

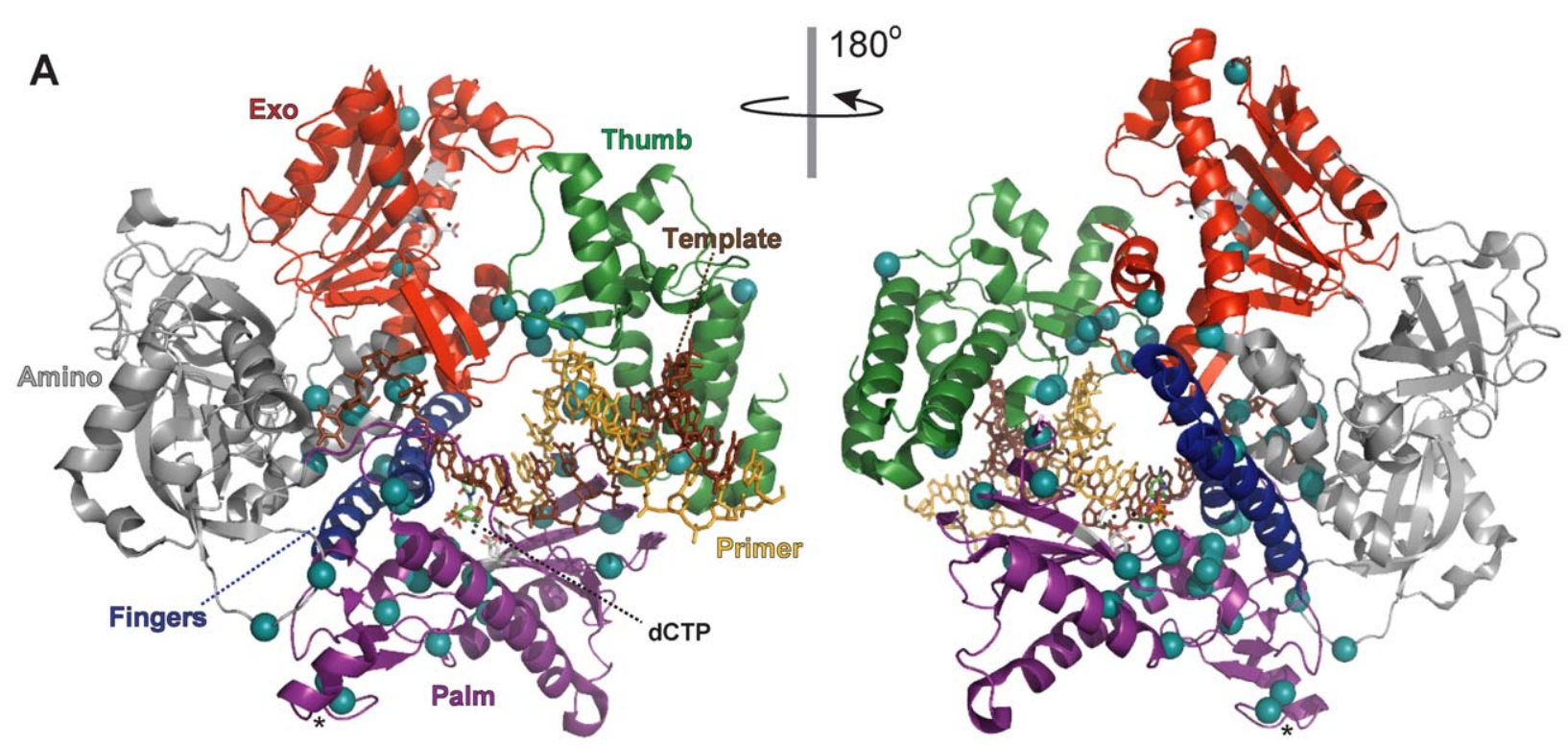

B
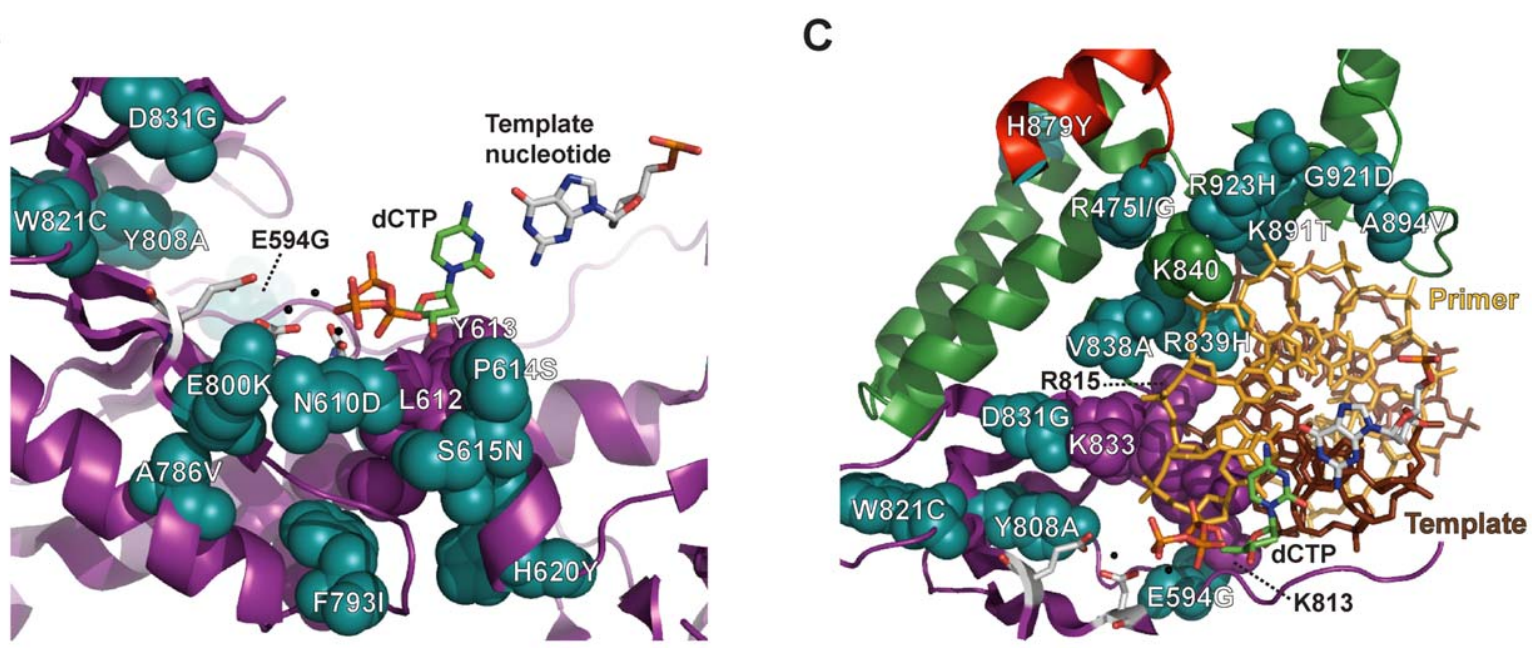

Figure 4. Locations of eex amino-acid substitutions in the $\boldsymbol{S}$. cerevisiae Pol $\delta$ structure. A) Overall distribution of eex amino-acid substitutions. The catalytic subunit of yeast Pol $\delta$ is shown as a ribbon diagram with color-coded structural domains: amino, gray; exonuclease (Exo), red; palm, purple; fingers, blue; thumb, green. Other important elements are indicated as follows: DNA template strand, brown sticks; DNA primer strand, yellow sticks; incoming dCTP, green CPK sticks; metal ions, small black spheres; active-site residues, gray CPK sticks extending out from the $\alpha$ carbon backbone in the palm and exonuclease domains. Residues changed by eex mutations are shown as light blue spheres. The asterisks mark adjacent E642K and D643N eex substitutions located on the solvent-exposed surface of Pol $\delta$. Structure from [74] (Protein Data Bank accession code 3IAY). B) Amino-acid substitutions near the polymerase active site. Palm domain eex residues are shown as space-filling spheres (light blue) and labeled to indicate the amino-acid substitutions. Important non-mutated residues proximal to the eex substitutions are also shown as space-filling spheres (purple). The fingers and thumb domains have been removed for clarity. C) Amino-acid substitutions in the DNA binding track. View looking down the DNA helical axis. The primer (yellow) and template (brown) are held by a series of interactions along the DNA minor groove. eex residues are light blue. Amino acids positioned by eex residues and minor-groove 'sensing' residues in the palm domain (K813, K814 and R815; [74]) are shown as space-filling spheres colored according to domain as in panel (A). The three unpaired 5 ' nucleotides of the template have been removed for clarity. doi:10.1371/journal.pgen.1002282.g004

tasis have been overcome. Although recent findings suggest that a mutator phenotype persists in at least some types of human tumors [23], our results raise the prospect that mutator phenotypes may be transient during tumor progression due to genetic suppression. An analysis of mutation rate dynamics in cancer is warranted.

\section{Materials and Methods}

\section{Media and Growth Conditions}

Yeast were grown at $30^{\circ} \mathrm{C}$ using YPD, synthetic complete (SC) media or SG drop-out media deficient in specific amino acids as needed to select for prototrophy [98]. Pre-formulated nutrient supplements for SC and SC lacking uracil and leucine were purchased from Bufferad. All other drop-out supplements were made as described [98]. URA3-deficient cells were selected on SC medium containing $1 \mathrm{mg} / \mathrm{ml}$ 5-fluroorotic-acid (FOA; Zymo Research) and an additional $50 \mathrm{mg} / \mathrm{L}$ uracil [43]. TRP1-deficient strains were selected on FAA selection media containing $0.5 \mathrm{mg} / \mathrm{ml}$ 5-fluroanthranillic acid (FAA) made as described [99]. Canavanineresistant mutants were scored on SC plates lacking arginine that contained $60 \mu \mathrm{g} / \mathrm{ml}$ of canavanine. Reagents were obtained from Sigma-Aldrich or Fisher Scientific unless otherwise indicated. 
Table 1. Mutation Rates $\left(\times 10^{-7}\right)$ of $p o / 3-01$,eex Mutant Strains.

\begin{tabular}{|c|c|c|c|c|c|c|c|}
\hline \multirow{3}{*}{$\begin{array}{l}\text { Allele } \\
\text { pol3-01 c }\end{array}$} & \multicolumn{4}{|c|}{$M S H 6^{\mathrm{a}}$} & \multicolumn{2}{|c|}{$m s h 6 A^{\mathrm{b}}$} & \multirow[t]{2}{*}{$\begin{array}{l}m s h 6 \Delta \\
\text { effect }\end{array}$} \\
\hline & \multicolumn{2}{|c|}{ FOA $^{r}$} & \multicolumn{2}{|l|}{ Can $^{r}$} & \multicolumn{2}{|l|}{$\operatorname{Can}^{r}$} & \\
\hline & 23 & $(19,26)$ & 135 & $(110,157)$ & - & & \\
\hline+ G207R & 6.2 & $(4.6,8.1)$ & - & & - & & \\
\hline$+\mathrm{H} 879 \mathrm{Y}$ & 5.7 & $(4.5,7.0)$ & 53 & $(41,65)$ & 11000 & $(7700,15000)$ & 209 \\
\hline$+Y 808 \mathrm{C}$ & 5.5 & $(4.2,7.0)$ & 31 & $(25,37)$ & 7700 & $(6300,9000)$ & 198 \\
\hline$+5968 R$ & 2.9 & $(2.1,3.8)$ & 34 & $(26,43)$ & 5200 & $(4100,6300)$ & 153 \\
\hline$+A 894 V$ & 2.4 & $(1.6,3.5)$ & 33 & $(25,40)$ & 3100 & $(2500,3700)$ & 96 \\
\hline+ G400S & 2.2 & $(1.6,3.0)$ & - & & - & & \\
\hline$+G 204 D$ & 2.1 & $(1.4,2.9)$ & 29 & $(22,36)$ & 4500 & $(3400,5600)^{d}$ & d 157 \\
\hline$+L 411 R$ & 1.8 & $(1.0,2.9)$ & - & & - & & \\
\hline+ E642K & 1.6 & $(1.1,2.4)$ & 23 & $(17,28)$ & 2600 & $(2000,3000)$ & 113 \\
\hline$+F 486 S$ & 1.6 & $(1.0,2.3)$ & - & & - & & \\
\hline$+T 711 A$ & 1.4 & $(1.0,2.0)$ & 33 & $(25,41)$ & 5900 & $(4700,7100)$ & 179 \\
\hline$+R 839 H$ & 1.4 & $(0.9,2.1)$ & - & & - & & \\
\hline$+W 821 C$ & 1.3 & $(0.8,1.9$ & 33 & $(24,41)$ & 2600 & $(2100,3000)$ & 80 \\
\hline$+C 365 Y$ & 1.3 & $(0.8,1.9)$ & - & & - & & \\
\hline$+A 786 \mathrm{~V}$ & 1.3 & $(0.8,1.9)$ & 12 & $(8,15)$ & 1600 & $(1200,1900)^{d}$ & d 135 \\
\hline$+F 7931$ & 1.2 & $(0.8,1.9)$ & 6 & $(4,8)$ & 1600 & $(1300,1800)$ & 258 \\
\hline$+R 475 G$ & 1.2 & $(0.8,1.8)$ & - & & - & & \\
\hline$+N 610 D$ & 1.1 & $(0.7,1.6)$ & - & & - & & \\
\hline$+\angle 531 P$ & 1.0 & $(0.7,1.6)$ & - & & - & & \\
\hline$+E 594 G$ & 1.0 & $(0.6,1.6)$ & 26 & $(17,35)^{d}$ & 1700 & $(1200,2100)$ & 63 \\
\hline$+R 475 I$ & 0.9 & $(0.5,1.5)$ & 14 & $(10,18)$ & 2700 & $(2300,3200)$ & 197 \\
\hline$+D 831 G$ & 0.9 & $(0.5,1.3)$ & 11 & $(8,15)$ & 1700 & $(1400,1900)$ & 150 \\
\hline + G921D & 0.9 & $(0.4,1.3)$ & - & & - & & \\
\hline$+D 643 N$ & 0.8 & $(0.4,1.5)$ & - & & - & & \\
\hline + V838A & 0.8 & $(0.5,1.3)$ & - & & - & & \\
\hline$+R 923 \mathrm{H}$ & 0.8 & $(0.4,1.3)$ & - & & - & & \\
\hline+ E800K & 0.7 & $(0.4,1.2)$ & 13 & $(10,17)$ & 1700 & (1400 1900) & 126 \\
\hline$+K 891 T$ & 0.7 & $(0.4,1.2)$ & 18 & $(14,23)$ & 1900 & (1500 2300) & 103 \\
\hline$+\mathrm{H} 62 \mathrm{OY}$ & 0.7 & $(0.4,1.1)$ & 15 & $(12,18)$ & 3700 & $(3000,4400)$ & 248 \\
\hline+ G731S & 0.5 & $(0.2,1.0)$ & - & & - & & \\
\hline$+S 615 N$ & 0.5 & $(0.3,0.9)$ & - & & - & & \\
\hline$+V 546 M$ & 0.5 & $(0.3,0.8)$ & 14 & $(10,19)$ & 2400 & $(1900,2800)$ & 171 \\
\hline+ G555S & 0.4 & $(0.2,0.8)$ & - & & - & & \\
\hline$+P 614 S$ & 0.4 & $(0.2,0.8)$ & 11 & $(8,15)$ & 2100 & $(1700,2400)$ & 185 \\
\hline$+Q 563 R$ & 0.3 & $(0.1,0.5)$ & 13 & $(9,17)$ & 2000 & $(1500,2500)$ & 158 \\
\hline$+1558 L$ & 0.3 & $(0.1,0.5)$ & - & & - & & \\
\hline
\end{tabular}

Rates of FOA or canavanine resistance (FOA ${ }^{r}$ or $\mathrm{Can}^{r}$ mutants per cell division) were determined by fluctuation analyses and maximum likelihood estimates using data from multiple independent experiments (except where noted). pol301,eex alleles are arranged from top to bottom according to the degree of mutator suppression as determined from rates of FOA resistance. Confidence intervals (95\%) are in parentheses. A dash (-) indicates the mutation rate was not determined.

${ }^{a}$ Mutation rates were determined in two different strains: FOA ${ }^{r}$, BP4001; Can ${ }^{r}$, YP6. ${ }^{\mathrm{b}}$ Mutation rates were determined in strain MP4.

cpol3-01,eex alleles not analyzed: 1616C, A677T, and P719T.

${ }^{\mathrm{d}}$ Mutation rate from a single experiment.

'The fold-increase in mutation rate caused by loss of MSH6 (msh64 effect) was calculated by dividing each pol3-01,eex msh6 4 mutation rate by the corresponding pol3-01,eex MSH6 rate. On average, msh64 increased mutation rate 157-fold. doi:10.1371/journal.pgen.1002282.t001
Table 2. Mutation Rates $\left(\times 10^{-7}\right)$ of pol3-eex Mutant Strains.

\begin{tabular}{|c|c|c|c|c|c|c|c|}
\hline \multirow{3}{*}{$\begin{array}{l}\text { Allele } \\
\text { POL3 }\end{array}$} & \multicolumn{4}{|c|}{$M S H \sigma^{\mathrm{a}}$} & \multirow{2}{*}{\multicolumn{2}{|c|}{$\frac{m s h 6 A^{\mathrm{b}}}{\operatorname{Can}^{\mathrm{r}}}$}} & \multirow[t]{3}{*}{$\begin{array}{l}\text { pol3-01 } \\
\text { effect }\end{array}$} \\
\hline & \multicolumn{2}{|c|}{ FOA $^{r}$} & \multicolumn{2}{|c|}{$\mathrm{Can}^{r}$} & & & \\
\hline & 0.3 & $(0.1,0.5)$ & 4.9 & $(4.0,5.8)$ & 23 & $(20,26)$ & \\
\hline$+G 207 R$ & 0.4 & $(0.2,0.7)$ & - & & - & & \\
\hline$+\mathrm{H} 879 \mathrm{Y}$ & 0.4 & $(0.2,0.6)$ & 1.9 & $(1.4,2.6)$ & 56 & $(44,67)$ & $198^{*}$ \\
\hline$+Y 808 C$ & 0.4 & $(0.2,0.7)$ & 2.1 & $(1.4,2.9)$ & 39 & $(30,48)$ & $198^{*}$ \\
\hline$+S 968 R$ & 0.3 & $(0.1,0.5)$ & 2.2 & $(1.6,2.8)^{d}$ & 23 & $(17,30)$ & $226^{*}$ \\
\hline+ A894V & 0.6 & $(0.3,0.9)$ & 2.7 & $(2.0,3.4)$ & 110 & $(88,130)$ & 29 \\
\hline+ G400S & 1.2 & $(0.8,1.8)$ & - & & - & & \\
\hline$+G 204 D$ & 0.7 & $(0.4,1.1)$ & 2.6 & $(1.9,3.4)$ & 54 & $(39,70)$ & $84^{*}$ \\
\hline$+E 642 K$ & 0.5 & $(0.2,1.0)$ & 7.0 & $(5.6,8.4)$ & 150 & $(120,180)$ & 17 \\
\hline$+F 486 \mathrm{~S}$ & 0.9 & $(0.6,1.4)$ & - & & - & & \\
\hline$+T 711 A$ & 0.3 & $(0.5,0.6)$ & 2.1 & $(1.7,2.4)$ & 22 & $(15,39)$ & $275^{*}$ \\
\hline$+\mathrm{R} 839 \mathrm{H}$ & 0.5 & $(0.2,0.9)$ & - & & - & & \\
\hline$+W 821 C$ & 0.3 & $(0.1,0.6)$ & 3.0 & $(2.3,3.8)$ & 33 & $(27,38)$ & $78^{*}$ \\
\hline$+C 365 Y$ & 0.3 & $(0.2,0.5)$ & - & & - & & \\
\hline$+A 786 \mathrm{~V}$ & 0.1 & $(0.0,0.3)$ & 6.1 & $(4.3,7.9)^{d}$ & 80 & $(63,98)$ & 19 \\
\hline$+F 7931$ & 0.2 & $(0.1,0.4)$ & 2.8 & $(2.0,3.6)^{d}$ & 89 & $(71,110)$ & 179 \\
\hline$+R 475 G$ & 0.2 & $(0.1,0.4)$ & - & & - & & \\
\hline$+N 610 D$ & 0.5 & $(0.2,0.9)$ & - & & - & & \\
\hline$+E 594 G$ & 0.2 & $(0.1,0.5)$ & 8.3 & $(5.5,11.2)^{d}$ & 15 & $(12,18)$ & $107^{*}$ \\
\hline$+R 4751$ & 0.4 & $(0.2,0.8)$ & 5.8 & $(3.6,8.3)^{d}$ & 160 & $(130,180)$ & 18 \\
\hline$+D 831 G$ & 0.9 & $(0.5,1.4)$ & 2.9 & $(2.1,3.7)$ & 64 & $(50,78)$ & 27 \\
\hline+ G921D & 0.4 & $(0.1,0.8)$ & - & & - & & \\
\hline$+V 838 A$ & 0.5 & $(0.3,0.9)$ & - & & - & & \\
\hline$+R 923 H$ & 0.2 & $(0.0,0.4)$ & - & & - & & \\
\hline$+E 800 K$ & 0.7 & $(0.4,1.2)$ & 3.6 & $(2.7,4.5)$ & 120 & $(97,160)$ & 14 \\
\hline$+K 891 T$ & 0.3 & $(0.1,0.5)$ & 6.6 & $(4.8,8.3)^{d}$ & 220 & $(180,260)$ & 9 \\
\hline$+\mathrm{H} 620 \mathrm{Y}$ & 0.3 & $(0.1,0.6)$ & 4.5 & $(2.8,6.5)^{d}$ & 26 & $(19,34)$ & $141^{*}$ \\
\hline+ G731S & 0.2 & $(0.1,0.5)$ & - & & - & & \\
\hline$+S 615 N$ & 0.3 & $(0.1,0.7)$ & - & & - & & \\
\hline$+V 546 M$ & 0.4 & $(0.2,0.7)$ & 4.3 & $(2.5,6.5)^{d}$ & 71 & $(49,93)^{d}$ & 33 \\
\hline+ G555S & 0.6 & $(0.3,1.0)$ & - & & - & & \\
\hline+ P614S & 0.5 & $(0.3,1.0)$ & 4.4 & $(3.3,5.6)$ & 130 & $(100,160)$ & 16 \\
\hline$+Q 563 R$ & 0.3 & $(0.1,0.6)$ & 4.3 & $(3.0,5.7)$ & 120 & $(98,140)$ & 17 \\
\hline$+1558 L$ & 0.5 & $(0.2,0.8)$ & - & & - & & \\
\hline
\end{tabular}

Rates of FOA or canavanine resistance (FOA ${ }^{r}$ or $\mathrm{Can}^{r}$ mutants per cell division) were determined by fluctuation analyses and maximum likelihood estimates using data from multiple independent experiments (except where noted). eex alleles are arranged from top to bottom in the same order as Table 1.

Confidence intervals $(95 \%)$ are in parentheses. A dash (-) indicates the mutation rate was not determined.

${ }^{a}$ Mutation rates were determined in two different strains: $\mathrm{FOA}^{r}$, BP4001; $\mathrm{Can}^{\mathrm{r}}$, YP6.

${ }^{\mathrm{b}}$ Mutation rates were determined in strain MP4

cpol3-eex alleles not analyzed: L411R, L531P, 1616C, D643N, A677T, and P719T. ${ }^{\mathrm{d}}$ Mutation rate from a single experiment.

${ }^{\mathrm{e}}$ The fold-increase in mutation rate caused by loss of Pol $\delta$ proofreading (po/301 effect) was calculated by dividing each pol3-01,eex msh64 mutation rate (Table 1 ) by the corresponding pol3,eex msh64 rate (above). pol3,eex msh64 strains marked with an asterisk $\left(^{*}\right)$ have mutation rates within 2 -fold of the POL3 msh64 strain, suggesting the eex alleles do not hamper primer partitioning or exonuclease function. In these strains, pol3-01 increased mutation rate an average of 163 -fold.

doi:10.1371/journal.pgen.1002282.t002 
A

\begin{tabular}{|c|c|c|c|c|}
\hline Allele & $\begin{array}{c}\text { Relative } \\
\text { Mutation } \\
\text { Rate } \\
\end{array}$ & $M M R^{+}$ & $m s h 6 \Delta$ & $m s h 2 \Delta$ \\
\hline POL3 & 1 & $0 B$ & $0 \%$ & 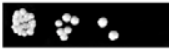 \\
\hline pol3-01 & 28 & O 5 & & \\
\hline$+H 879 Y$ & 11 & 붕 & s & \\
\hline$+T 711 A$ & 7 & $0+6$ & 楆 & 8 \\
\hline$+S 968 R$ & 7 & O 58 & b & \\
\hline$+A 894 \mathrm{~V}$ & 7 & $08:$. & 1) 물 & \\
\hline$+Y 808 \mathrm{C}$ & 6 & $0 \%$ \& & is: & \\
\hline$+G 204 D$ & 6 & 0 황 & sis & \\
\hline$+E 642 K$ & 5 & O 8 . & 0.8. & - \\
\hline$+K 891 T$ & 4 & $0 \approx:$ & 0 炡 & 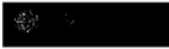 \\
\hline$+R 475 I$ & 3 & 0034 & e & 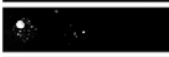 \\
\hline$+V 546 M$ & 3 & 0 영 & $0+3$ & 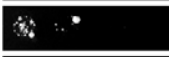 \\
\hline$+Q 563 R$ & 3 & 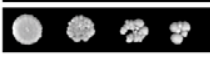 & 0 s & 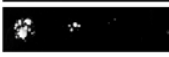 \\
\hline$+H 620 Y$ & 3 & $0 \div 0$ & $0 \%$ & 4 \\
\hline$+E 800 K$ & 3 & O웅 : & 0 : :- & 称 \\
\hline$+D 831 G$ & 2 & 0 檽: & 0 : : & 44 \\
\hline$+A 786 \mathrm{~V}$ & 2 & 0 争" & 0 : & 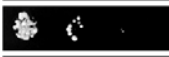 \\
\hline$+P 614 S$ & 2 & 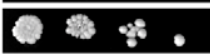 & $0 *$ & 0 湾: \\
\hline$+F 7931$ & 1 & 0 舫 & $0 \%$ & $\theta$ 항. \\
\hline
\end{tabular}

B

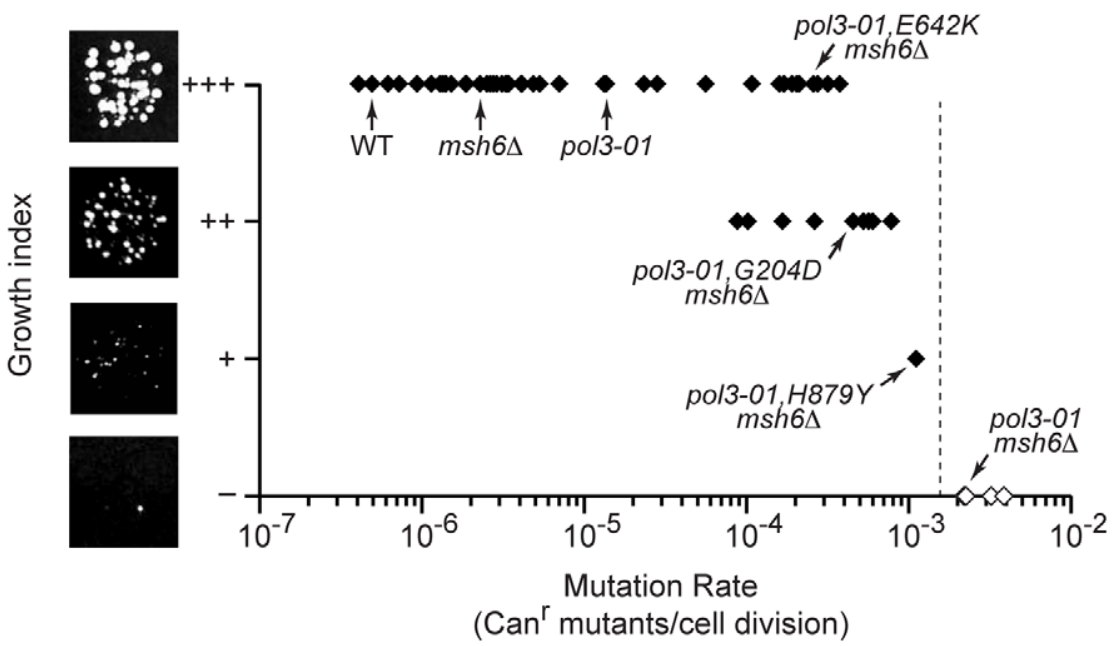

Figure 5. Defining the threshold of error-induced extinction. A) Plasmid shuffling experiments to reveal synthetic interactions between pol301 ,eex alleles and MMR mutations. Ten-fold serial dilutions of yeast containing POL3-URA3 and pol3-LEU2 plasmids were plated on FOA-containing SC medium to select for cells that spontaneously lost POL3-URA3. Similar numbers of colony forming units were plated for each set of alleles in the $M M R^{+}, m s h 6 \Delta$ and $m s h 24$ strains. Failed growth indicates synthetic lethality. Small colonies reflect slow-growth phenotypes. Relative mutation rates are the $\mathrm{Can}^{r}$ mutation rates conferred by each pol3 allele relative to wild-type POL3 in MMR-proficient cells (see Table 1 and Table 2). Alleles are listed in decreasing order of mutator strengths. Some alleles with statistically similar mutation rates (as reflected by overlapping confidence intervals) have slightly different relative rates due to mathematical round-off. B) Relationship between growth capacity and CAN1 mutation rate for 62 haploid yeast strains. Colonies of pol3-01,E642K msh64, pol3-01,G204D msh64, pol3-01,H879Y msh64, and pol3-01 msh64 cells are shown to illustrate wild-type $(+++)$, moderately defective $(++)$, severely defective $(+)$, and failed $(-)$ growth, respectively. The vertical dashed line indicates the estimated maximal mutation rate compatible with haploid yeast colony formation, which is our functional definition of the replication error threshold. Filled symbols, rates measured by fluctuation analyses. Open symbols, rates estimated as described in the text. Data in brackets with an asterisk (*) are pol3-01,T711A msh64, pol3-01,S968R msh64, pol3-01,G204D msh64, and pol3-01,Y808C msh64.

doi:10.1371/journal.pgen.1002282.g005 


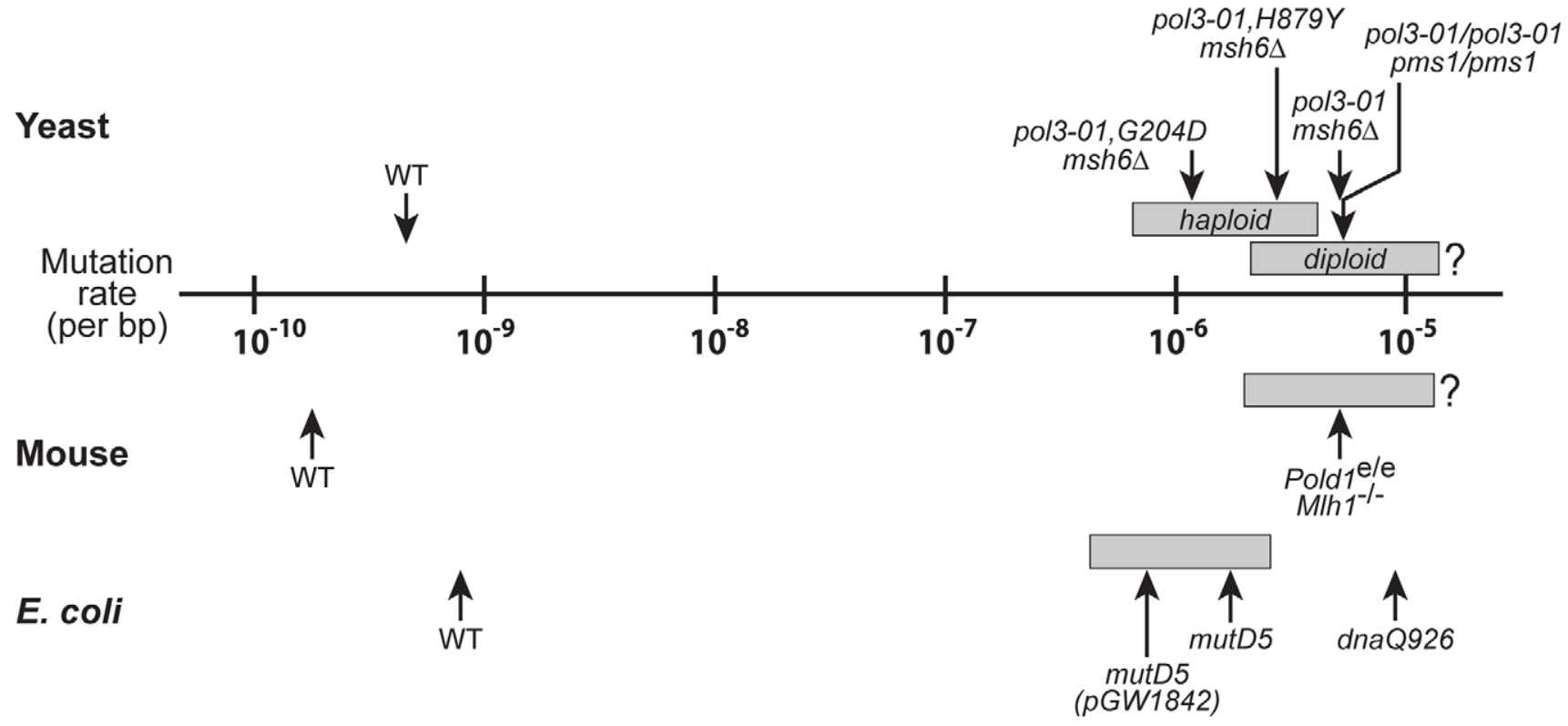

Figure 6. Mutational robustness of yeast, $E$. coli, and mice. Comparison of spontaneous per-base-pair mutation rates of wild-type (WT) and strong mutator strains of yeast (haploid and diploid), E. coli and mouse cells. Gray boxes indicate the mutation rate intervals that coincide with the transition from wild-type growth (leftmost boundary) to failed growth (rightmost boundary). The data for haploid yeast mutators are from Figure 5B, with the left boundary corresponding to the mutation rate of pol3-01,E642K msh64 cells $\left(6.5 \times 10^{-7}\right)$ and the right boundary corresponding to the lethal threshold $\left(4.1 \times 10^{-6}\right)$. The mutation rates of pol3-01,G204D msh64, pol3-01,H879Y msh64, and pol3-01 msh64 haploid yeast are shown as examples of progressively stronger mutators with slow (++), very slow (+) and no-growth (-) phenotypes, respectively. The data for po/3-01/pol3-01 pms 1/pms 1 diploid yeast are from Morrison et al. [40]; pol3-01/pol3-01 pms 1/pms1 cells divide very slowly with a growth phenotype presumably in the range of + to ++ . The mouse Pold $1^{e / e} M / h 1^{4 / \Delta}$ mutation rate is extrapolated from ouabain-resistance rates of cultured Pold $1^{+/ e} M / h 1^{1 / 4}$ fibroblasts as described in Materials and Methods; a growth phenotype between + and ++ is assumed [25]. E. coli mutation rates and growth phenotypes are from Fijalkowska et al. [62]; mutD5(pGW1842), mutD5 and dnaQ926 exhibit slow (++), very slow (+) and no-growth (-) phenotypes, respectively. The positions of the gray boxes for diploid yeast, mouse and $E$. coli are estimates based on the mutation rate and growth capacity relationships observed in haploid yeast (Figure 5B). The error thresholds (rightmost boundaries) for diploid yeast and mouse cells are not known. The yeast wild-type rate is the average of multiple independent determinations (data herein and $[40,108,114,124]$ ). Wild-type mouse and $E$. coli mutation rates are from Drake et al. $[9,114]$.

doi:10.1371/journal.pgen.1002282.g006

\section{Yeast Plasmids and Strains}

Plasmids. pGL310 is the CEN4/ARS1/URA3 plasmid, YCp50 [100], modified to carry SUP11 and the wild-type POL3 gene under control of its native promoter [29,101]. YCplac111POL3 and YCplac111pol3 derivatives are CEN4/ ARS1/LEU2 plasmids derived from YCplac111 [102] and contain the entire wild-type POL3 or mutant pol3 genes (with native promoters) flanked by HindIII and EcoRI restriction sites. pRS414POL3 and pRS414pol3-01 are derivatives of the CEN6/ ARS4/TRP1 plasmid, pRS414 [103], carrying the HindIIIEcoRI POL3 DNA fragments from YCplac111POL3 and YCplac111pol3-01, respectively. The construction of YCplac111 and pRS414 vectors and subsequent subcloning of eex mutants are described in detail in Text S1.

Strains. Yeast strains and their genotypes are listed in Table S3. Chromosomal gene disruptions were introduced using PCR products generated with primers, templates, and protocols detailed in Table S4 and Text S1. YGL27-3D (a kind gift from Michel Simon and Gerard Faye, Institut Curie) is a haploid strain that carries a lethal, partial deletion of chromosomal POL3 substituted by HIS3 and complemented by pGL310. Chromosomal MSH6 was replaced with TRP1 to create YGL27-3Dmsh6dis4. To limit gene conversion between the pol3 plasmids and residual POL3 sequences in the chromosome, the entire POL3 coding sequences in YGL27-3D and YGL27-3Dmsh6dis4 were replaced with kanMX [104], creating YP6 (previously called YGL27-pol34 [105]) and MP4, respectively.
The S288c derivative, BY4733 [103], was modified to create a set of isogenic strains in a standard genetic background. BY4733 was transformed with pGL310, and chromosomal POL3 was deleted and replaced with HIS3 to create P3H3a. MSH2 was deleted in $\mathrm{P} 3 \mathrm{H} 3 \mathrm{a}$ and replaced with TRP1 to create BP0109. MSH6 was deleted in $\mathrm{P} 3 \mathrm{H} 3 \mathrm{a}$ and replaced with $\operatorname{kanMX}$ [106] to create $\mathrm{BP} 1506$. $\mathrm{P} 3 \mathrm{H} 3 \mathrm{a}$ was modified as follows to allow mutation rate measurements at URA3. First, $\mathrm{P} 3 \mathrm{H} 3$ a was transformed with pRS414POL3 and plated on SC FOA to isolate a strain that lost pGL310. Then, to create BP4001, AGP1 on Chromosome III was replaced with URA3 oriented with the direction of transcription towards ARS306 [107].

\section{Plasmid Shuffling}

Plasmid shuffling with pGL310-containing strains was carried out essentially as described [29,43] (Figure S1). Cells transformed with YCplac1 11 pol3 plasmids, YCplac111 POL3 (positive control), or YCplac111 (negative control) were plated on SC lacking uracil and leucine. Cells transformed with pRS414pol3-01, pRS414POL3 (positive control), or pRS414 (negative control) were plated on SC lacking uracil and tryptophan. After three days at $30^{\circ} \mathrm{C}$, individual colonies were picked and resuspended in sterile $\mathrm{H}_{2} \mathrm{O}$, and serial dilutions containing approximately $10^{5}, 10^{4}, 10^{3}$, or $10^{2}$ cells were plated onto $\mathrm{SC}$ or $\mathrm{SC}$ FOA to select for clones that spontaneously lost the URA3 plasmid pGL310. A similar approach was used for shuffling in strains carrying the TRP1 plasmid pRS414POL3; BP4001 transformants containing both pRS414POL3 and YG- 
plac111-based plasmids were selected on SC lacking tryptophan and leucine and then plated onto SC FAA to select for clones that spontaneously lost the TRP1 plasmid.

\section{eex Mutant Screen}

For the systematic isolation of spontaneous pol3-01,eex mutant alleles (Figure 2C), a pol3-01 plasmid was transformed into pol3 4 $m s h 64+$ pGL310 yeast, and $1-5 \times 10^{6}$ cells from independent transformants were plated separately on SC FOA. FOA-resistant clones were isolated in the MP4 strain carrying YCplac111 pol3-01 or in BP1506 carrying YCplac111pol3-01 or pRS414pol3-01. Bona fide eex mutants were distinguished from FOA-resistant clones that result from ura3 mutation or pol3-01 $\rightarrow$ POL3 gene conversion by using a genotyping assay described in Text S1. pol3-01 plasmids from individual eex mutants were recovered and reshuffled into naïve pol34 msh64 + pGL310 cells to identify suppressors intragenic to pol3-01. Plasmids that conferred consistent survival upon reshuffling were purified, and the pol3 genes were sequenced (primer sequences available on request). Intragenic eex alleles thus identified were individually re-engineered into fresh YCplac111POL3 and YCplac111pol3-01 vectors and re-transformed into MP4 or BP1506 stock strains as a final confirmation of the ability of each allele to confer the eex phenotype. The re-engineered mutants were used to assess the effects of eex alleles on mutation rates and plating efficiencies.

\section{Mutation Frequencies and Rates}

For the scanning mutagenesis screen (Figure S2), sequenceverified YCplac111pol3 plasmids were shuffled into YP6 or MP4 cells immediately prior to each experiment. Twelve to thirteen independent FOA-resistant colonies of each genotype were streaked onto SC plates in $\sim 1$-cm patches, grown two days at $30^{\circ} \mathrm{C}$, and then replica-plated to canavanine plates to qualitatively assess mutant frequencies based on the number of canavanineresistant colonies [47] (Figure S2A).

To measure mutation rates at the $C A N 1$ locus, freshly streaked YP6 or MP4 strains were transformed with YCplac111POL3 or YCplac111pol3 plasmids, and multiple independent transformants were shuffled on SC FOA plates to obtain well-isolated single colonies. For each genotype, seven to eleven independent colonies, 1-2 $\mathrm{mm}$ in diameter, were excised as an agar plug, resuspended in $1 \mathrm{ml}$ of $\mathrm{dH}_{2} \mathrm{O}$, and sonicated briefly. To estimate the number of cell divisions $(\mathrm{Nt})$ during colony formation, serial dilutions were plated on SC media, and the number of colonyforming units was counted after two days at $30^{\circ} \mathrm{C}$. To determine the number of mutants for wild-type and weak mutator strains, all of the remaining cells were plated on canavanine plates; for stronger mutators, the cell suspension was diluted 1:10 to 1:200 in $\mathrm{dH}_{2} \mathrm{O}$ prior to plating. The numbers of canavanine-resistant colonies on each plate were scored after three to four days at $30^{\circ} \mathrm{C}$.

To measure URA3 mutation rates, BP4001 was transformed with YCplac111POL3, YCplac111pol3-01, or their respective eex mutant derivatives. Four FAA-resistant colonies from independent transformants with each plasmid were inoculated into separate 100- $\mu \mathrm{l} \mathrm{SC}$ overnight cultures. The following morning the cultures were diluted to 1000 cells $/ \mathrm{ml}$ and, for each of the four isolates, 12 parallel $100-\mu \mathrm{l}$ cultures (100 cells/culture) were set up in 96-well microtiter plates. The plates were sealed with adhesive PGR plate sealers (Abgene, AB-0558) to minimize evaporation [108]. After two days of growth at $30^{\circ} \mathrm{C}$, the cells were re-suspended by vigorous vortexing, and nine of the replicate cultures were spot-plated in $200-\mu \mathrm{l}$ volumes on SC FOA plates. To estimate the total number of cell divisions, the remaining three replica cultures from each isolate were combined, diluted, and plated on SC plates. Colony numbers were scored after 3-4 days. We confirmed that spot plating accurately determines the number of FOA-resistant colonies for the strongest mutator by dividing test cell suspensions in half and comparing colony counts in a $100-\mu \mathrm{l}$ spot with $100 \mu \mathrm{l}$ of the same suspension spread over an entire SC FOA plate.

Mutation rates were determined from the number of mutant colonies in each replica by calculating an estimate for $m$ by maximum likelihood [109] using newtonLD in Salvador 2.1 [110] with Mathematica 6.0 (Wolfram Research) and dividing by the number of cell divisions inferred from colony forming units. Where values for $\mathrm{Nt}$ from independent experiments differed by less than 2-fold, the data sets were combined for the mutation rate calculations [109]. In some instances, Nt values from independent experiments differed by more than 2-fold. In most cases, the independently-derived mutation rates were similar and a single value was reported (noted in Table 1). Confidence intervals were calculated in Salvador 2.1 using LRIntervalLD, which relies on likelihood ratios [110].

From these mutation rates, the efficiency of Msh6-dependent MMR $\left(e_{m 6}\right)$, expressed as the percentage of errors corrected, was calculated using equation 1 :

$$
\begin{aligned}
& e_{m 6}=\left[\left(M r_{m s h 6 \Delta p o l 3-01, e e x}-M r_{M S H 6 \Delta p 1 o l 3-01, e e x}\right)\right. \\
& \left./ M r_{m 1 s h 6 \Delta p o l 3-01, e e x}\right] \times 100
\end{aligned}
$$

where $M r$ is the relative mutation rate of the strain indicated in the subscript. The efficiency of Pol $\delta$ proofreading $\left(e_{\text {dexo }}\right)$, expressed as a percentage of errors corrected, was calculated similarly from equation 2:

$$
\begin{aligned}
& e_{\text {¿exo }}=\left[\left(M r_{m s h 6 \Delta p o l 3-01, e e x}-M r_{m s h 6 \Delta p o l 3-e e x}\right)\right. \\
& \left./ M r_{m s h 6 \Delta p o l 3-01, e e x}\right] \times 100
\end{aligned}
$$

\section{CAN1 Mutation Spectra}

For each strain, we isolated up to 48 canavanine-resistant mutants from 48 independent shuffling experiments. Cells were treated with Zymolyase (ICN Biomedicals; $50 \mathrm{u} / \mathrm{ml}$ in $10 \mathrm{mM}$ Tris $\bullet \mathrm{HCl} / 0.1 \mathrm{mM}$ EDTA, pH7.5 at $37^{\circ} \mathrm{C}$ for $30 \mathrm{~min}$ then $95^{\circ} \mathrm{C}$ for $10 \mathrm{~min}$ ), and the can 1 coding sequence was PCR-amplified in $50-\mu$ l reactions with Phusion polymerase (NEB) using primers can 1 F1N (5'-GGTTAAGATAAGTAGATAAGAGAATGATACG-3') and can $1 \mathrm{~S} 1$ (5'-GGGTGGAAATGTGATCAAAGG-3') with the following PCR conditions: $98^{\circ} \mathrm{C}, 1 \mathrm{~min}$; $35 \times\left(98^{\circ} \mathrm{C}\right.$, 10 sec.; $45^{\circ} \mathrm{C}$, 30 sec.; $72^{\circ} \mathrm{C}, 90$ sec.); $72^{\circ} \mathrm{C}, 1 \mathrm{~min}$. The samples were treated with 5 units each of Antarctic phosphatase and Exol (New England Biolabs) to degrade excess primer and dNTPs, heated at $80^{\circ} \mathrm{C}$ for $20 \mathrm{~min}$ to inactivate the enzymes, and then sequenced with primers canlS1, canlS2 (5'-CGAAAGCGCCAAATGCAGCAG-3'), can1S3 (5'-TGCAATAAGGGAATCCAACTG- $\left.3^{\prime}\right)$ and can $1 \mathrm{~S} 4$ (5'-GGGCAATCATACCAATATGTC- $\left.3^{\prime}\right)$. Mutation spectra were tabulated and compared using iMARS [111].

\section{Per-Base-Pair Mutation Rates}

Phenotypic mutation rates were converted to per-base-pair rates using the approach of Drake [112-114] according to equations 3 5 : 


$$
\begin{gathered}
C=\left(B_{C T} / B\right)(64 / 3) \\
C^{\prime}=(I+C \cdot B) / M \\
\mu_{b}=\mu_{T} \times C^{\prime} / T
\end{gathered}
$$

$C$ and $C^{\prime}$ (equations 3 and 4 ) are correction factors to adjust for undetected (phenotypically silent) base-substitution mutations in a reporter gene. $B_{C T}=$ the number of chain-terminating base substitutions (3 possible codons), $B=$ the number of all base substitutions (64 possible codons), and $I=$ the number of insertions+deletions (indels) in representative mutation spectra from $M$ mutants sequenced. The mutation rate per base pair $\left(\mu_{b}\right)$ is calculated using equation 5 from the experimentally determined phenotypic mutation rate $\left(\mu_{T}\right)$ multiplied by the correction factor $C^{\prime}$ and divided by the number of base pairs in the mutationreporter target sequence $(T)$. The effective target size $(\tau)$ is estimated by $T / C^{\prime}$.

In our collection of $484 \mathrm{Can}^{\mathrm{r}}$ mutants from proofreading- and MMR-deficient yeast (Figure S3 and Table S2), there were 442 base substitutions (101 chain-terminating +341 missense) and 42 indels (including infrequent complex mutations) in CAN1 ( $T=1773$ ). Thus, $C=4.87$ and $\tau=391$ base pairs. These values from mutator yeast strains are similar to those previously determined by others scoring spontaneous mutation in wild-type yeast $(C=4.73,[113] ; \tau=236,[108])$. The per-base-pair rates for haploid yeast plotted in Figure 6 were calculated from our $\operatorname{Can}^{\mathrm{r}} \mu_{T}$ values (Table 1 and Table 2) with $C=4.87, C^{\prime}=4.53$ and $T=1773$. For diploid pol3-01/pol3-01 pms1/pms1 yeast, we used the $\mathrm{FOA}^{\mathrm{r}}$ mutation rate $\left(\mu_{T}\right)$ of $3.5 \times 10^{-4}$ reported by Morrison et. al. [40]; $C=8.18$ (determined from the data of Lang and Murray [108]), $C^{\prime}=6.79$ and $T=804$ base pairs for the URA3 target gene. Thus, $\tau$ is 118 base pairs, and the per-base-pair mutation rate of pol3-01/pol3-01 pms1/pms1 diploids at the URA3 locus is $\left[\left(3.5 \times 10^{-4}\right) \times 6.79 / 804\right]=3.0 \times 10^{-6}$. In Figure 6 we multiply this rate by 1.8 to adjust for the lower intrinsic mutation rate of URA3 compared to CAN1 (Table 1 and Table 2 and [108]).

For mouse cells, per-base-pair mutation rates were calculated from ouabain-resistance $\left(\mathrm{Oua}^{\mathrm{r}}\right)$ rates determined in our laboratory using spontaneously immortalized mouse embryo fibroblasts ([25] and unpublished data). The effective target size $(\tau)$ is estimated as follows. Base substitution mutations in any one of sixteen codons in the $\mathrm{Na}, \mathrm{K}$-ATPase $\alpha \mathrm{l}$ gene (Atp1al) are known to confer genetically dominant resistance to $\mu \mathrm{M}$ concentrations of ouabain in human cells [115]. Mouse cells, however, are naturally resistant to $\mu \mathrm{M}$ concentrations of ouabain due to differences at 2 of these 16 codons (Q111R and N122D; [116,117]. Our fluctuation assays were conducted with $2 \mathrm{mM}$ ouabain [25], conditions expected to only detect mutations that confer exceptionally high ouabain resistance. We estimate the target size to be $\sim 5$ base pairs per allele, corresponding to two Atp1a1 codons (D121 and T797) known to effect $>50$-fold ouabain-resistance when mutated $[115,118]$. Mouse fibroblast cell lines are typically tetraploid [119]. Therefore $\tau=5$ base pairs per allele $\times 4$ alleles $=20$ base pairs. Pold ${ }^{+/ e} M l h 1^{\Delta / \Delta}$ cells, which are heterozygous defective for Pol $\delta$ proofreading and nullizygous for MMR, exhibited a mutation rate of $65 \times 10^{-7}$ Oua $^{\mathrm{r}}$ mutants per cell division $(95 \%$ confidence interval $\left.=56-75 \times 10^{-7}\right)$. This phenotypic rate corresponds to a per-base-pair rate of $65 \times 10^{-7} / 20$ base pairs $=3.3 \times 10^{-7}$. Mouse cells that are homozygous deficient for both Pol $\delta$ proofreading and MMR (Pold1 $1^{e / e}$ Mlh $1^{\Delta / \Delta}$ ) are viable but divide slowly up to embryonic day E9.5 [25]. Based on the relative mutation rates of $M M R^{\Delta / \Delta}$ diploid yeast with +/- or $-/-\operatorname{Pol} \delta$ proofreading alleles [40], we estimate the per-base-pair rate of Pold $1^{e / e}$ Mlh $1^{\Delta / \Delta}$ mouse cells to be $5 \times 10^{-6}$.

\section{Supporting Information}

Figure S1 Plasmid shuffling strategy. Mutated pol3 alleles were introduced into MSH6 and msh64 yeast by plasmid shuffling. Haploid yeast with a chromosomal deletion of POL3 (pol34) complemented by a wild-type POL3-URA3 plasmid (left) are transformed with mutant pol3-LEU2 plasmids. Individual colonies carrying both the pol3 and POL3 plasmids are isolated (center), and dispersed cells are then plated on 5-fluoroorotic acid (FOA) media to select mutant pol3-LEU2 clones that lost the wild-type POL3URA3 vector (right).

(PDF)

Figure S2 Mutagenesis screen of the Pol $\delta$ exonuclease domain. Each allele was engineered into a wild-type POL3 vector (YCplac111POL3) by site-directed mutagenesis and then introduced into yeast by plasmid shuffling (see Figure S1). Independent FOA-resistant colonies were patched onto synthetic complete (SC) plates and then replica-plated to $\mathrm{SC}$ plates lacking arginine and containing canavanine $(60 \mu \mathrm{g} / \mathrm{ml})$ to assess mutator phenotypes [47]. A) Representative canavanine plates used to assess mutator phenotypes. Each plate has twelve or thirteen patches of cells derived from independent colonies of the indicated genotypes. Spontaneous canavanine-resistant $\left(\mathrm{Can}^{\mathrm{r}}\right)$ mutants appear as small colonies in the $\sim 1-\mathrm{cm}$ patches. Mutant frequencies were qualitatively judged from the lowest (wild type, WT) to highest (pol3-G400A msh64) as indicated by,,-+++ and +++ scores. B) Summary of POL3 alleles and corresponding mutator and growth phenotypes in MSH6 and msh64 cells.

(PDF)

Figure S3 Spontaneous CAN1 mutations from pol3-01,eex msh64 cells. The can 1 coding sequences from 30-48 independent canavanine-resistant $\left(\mathrm{Can}^{\mathrm{r}}\right)$ mutants of each strain were PCRamplified and sequenced. Spontaneous mutations identified in different strains are color coded according to the key at the bottom. Each base letter above the wild-type CAN1 sequence indicates the site and nature of an independent base substitution or frameshift (+ or -) mutation. CAN1 sequences involved in complex mutations are indicated by horizontal colored lines. Multiple mutations identified in can 1 from the same mutant clone are designated by the same superscript in the same color code. We observed mutation hotspots in CAN1 that arose in multiple independent $\mathrm{Can}^{\mathrm{r}}$ clones. One hotspot, a $\mathrm{C}$ to $\mathrm{T}$ mutation at $\mathrm{nt}$ 899, occurred in eight independent pol3-01,K891 T Can $^{\mathrm{r}}$ clones. Two of the eight mutants had a second mutation elsewhere in the CAN1 sequence, unambiguously identifying each clone as unique. This suggests that the abundance of mutations at this site is unlikely to be an artifact. One Can ${ }^{\mathrm{r}}$ POL3 msh64 mutant (not shown) contained an insertion/deletion mutation that was evident by a larger PCR product; sequencing with nested $C A N 1$-specific primers revealed an insertion containing the gene RRP45. (PDF)

Figure S4 Similar cell morphologies in yeast after error extinction or repression of essential genes. Black bars: terminal cell morphologies of pol3-01 pms14 haploid cells that ceased growing due to error extinction [40]. White bars: cell-cycle arrest phenotypes of 563 haploid strains, each with a different repressed essential gene [59]. In the repression study, 82 additional essential 
genes showed a growth defect but with no defined cell-cycle arrest phenotype.

(PDF)

Figure S5 eex amino-acid substitutions near the template nucleotide in Pol $\delta$. Schematic of the $\alpha$-carbon backbone of Pol $\delta$ with residues of interest depicted as space-filling spheres. Structural elements are color-coded as in Figure 4 with the template $\mathrm{dNTP}\left(\mathrm{T}_{0} \mathrm{P}_{0}\right)$ and polymerase active-site residues shown as CPK sticks. Amino acids changed by eex mutations are shown as light blue spheres and labeled to indicate the eex substitutions. Residues V546, G555, I558, and Q563 from the amino domain are in three closely associated $\alpha$-helices that bind the template and buttress the fingers domain. The exo domain has been removed for clarity, and the penultimate $\mathrm{T}_{1} \mathrm{P}_{1}$ base-pair (brown and gold spheres) is included to delineate the binding pocket. Panel (A) is a view looking down on the DNA major groove. Panel $(B)$ is the same image rotated $90^{\circ}$ around the $\mathrm{x}$-axis. The $\mathrm{T}_{1} \mathrm{P}_{1}$ base-pair was removed in Panel (B) to reveal positions of amino-acid substitutions around the template $\bullet$ NTP. Structure from [74] (Protein Data Bank accession code 3IAY).

(PDF)

Figure S6 eex amino-acid substitutions in the exonuclease domain of Pol $\delta$. The exo domain (red) is shown as a schematic of the $\alpha$-carbon backbone, and exonuclease active-site residues are gray CPK sticks. Amino acids changed by eex mutations are shown as light blue spheres and labeled to indicate the eex substitutions. The red dotted line corresponds to a missing loop in the structure (amino acids 491-496). The $\beta$-hairpin in T4 and RB69 pols affects partitioning of the primer between polymerase and exonuclease

\section{References}

1. Friedberg EC, Walker GC, Siede W, Wood RD, Schultz RA, et al. (2006) DNA Repair and Mutagenesis. Washington, D.C.: ASM Press.

2. McCulloch SD, Kunkel TA (2008) The fidelity of DNA synthesis by eukaryotic replicative and translesion synthesis polymerases. Cell Res 18: 148-161.

3. Iyer RR, Pluciennik A, Burdett V, Modrich PL (2006) DNA mismatch repair: functions and mechanisms. Chem Rev 106: 302-323.

4. Reha-Krantz LJ (2010) DNA polymerase proofreading: Multiple roles maintain genome stability. Biochim Biophys Acta 1804: 1049-1063.

5. de Visser JA (2002) The fate of microbial mutators. Microbiology 148: $1247-1252$.

6. Giraud A, Radman M, Matic I, Taddei F (2001) The rise and fall of mutator bacteria. Curr Opin Microbiol 4: 582-585.

7. Sturtevant AH (1937) Essays on evolution. I. On the effects of selection on mutation rate. Q Rev Biol 12: 464-467.

8. Denamur E, Matic I (2006) Evolution of mutation rates in bacteria. Mol Microbiol 60: 820-827.

9. Drake JW, Charlesworth B, Charlesworth D, Crow JF (1998) Rates of spontaneous mutation. Genetics 148: 1667-1686.

10. Elena SF, Lenski RE (2003) Evolution experiments with microorganisms: the dynamics and genetic bases of adaptation. Nat Rev Genet 4: 457-469.

11. Chao L, Cox EC (1983) Competition between high and low mutating strains of Escherichia coli. Evolution 37: 125-134.

12. Sniegowski PD, Gerrish PJ, Lenski RE (1997) Evolution of high mutation rates in experimental populations of E. coli. Nature 387: 703-705.

13. Mao EF, Lane L, Lee J, Miller JH (1997) Proliferation of mutators in a cell population. J Bacteriol 179: 417-422.

14. Giraud A, Matic I, Tenaillon O, Clara A, Radman M, et al. (2001) Costs and benefits of high mutation rates: adaptive evolution of bacteria in the mouse gut. Science 291: 2606-2608.

15. Nilsson AI, Kugelberg E, Berg OG, Andersson DI (2004) Experimental adaptation of Salmonella typhimurium to mice. Genetics 168: 1119-1130.

16. Notley-McRobb L, Seeto S, Ferenci T (2002) Enrichment and elimination of mutY mutators in Escherichia coli populations. Genetics 162: 1055-1062.

17. Funchain P, Yeung A, Stewart JL, Lin R, Slupska MM, et al. (2000) The consequences of growth of a mutator strain of Escherichia coli as measured by loss of function among multiple gene targets and loss of fitness. Genetics 154: 959-970.

18. Tröbner W, Piechocki R (1984) Selection against hypermutability in Escherichia coli during long term evolution. Mol Gen Genet 198: 177-178.

19. Schaaper RM, Cornacchio R (1992) An Escherichia coli dnaE mutation with suppressor activity toward mutator mutD5. J Bacteriol 174: 1974-1982. active sites [4]. Structure from [74] (Protein Data Bank accession code 3IAY).

(PDF)

Table S1 Genotypes of candidate eex mutants.

(PDF)

Table S2 Types of spontaneous CAN1 mutations in pol3-01,eex $m s h 64$ strains.

(PDF)

Table S3 Yeast strains.

(PDF)

Table S4 Construction of chromosomal gene disruptions.

(PDF)

Text S1 Supplementary methods.

(PDF)

\section{Acknowledgments}

We thank Tim Formosa and David Stillman for technical guidance, yeast strains, and vectors and valuable discussions during the initial stages of this project; Dan Dennis, Jenny Sherpa, Elise Olmsted, and Melissa Nakaoka for technical assistance; Michel Simon and Gerard Faye for providing yeast strains; and Tina Albertson, Jesse Salk, and Larry Loeb for critical reading of the manuscript.

\section{Author Contributions}

Conceived and designed the experiments: AJH MO NAL LNW MS RAS BDP. Performed the experiments: AJH MO NAL JME LNW MS. Analyzed the data: AJH MO NAL JME MS RAS BDP. Contributed reagents/materials/analysis tools: AJH MO NAL LNW JME MS RAS BDP. Wrote the paper: AJH RAS BDP.

20. Fijalkowska IJ, Schaaper RM (1995) Effects of Escherichia coli dnaE antimutator alleles in a proofreading-deficient mutD5 strain. J Bacteriol 177: 5979-5986.

21. Loeb LA, Springgate GF, Battula N (1974) Errors in DNA replication as a basis of malignant changes. Cancer Res 34: 2311-2321.

22. Loeb LA, Bielas JH, Beckman RA (2008) Cancers exhibit a mutator phenotype: clinical implications. Cancer Res 68: 3551-3557.

23. Bielas JH, Loeb KR, Rubin BP, True LD, Loeb LA (2006) Human cancers express a mutator phenotype. Proc Natl Acad Sci USA 103: 18238-18242.

24. Goldsby RE, Lawrence NA, Hays LE, Olmsted EA, Chen X, et al. (2001) Defective DNA polymerase- $\delta$ proofreading causes cancer susceptibility in mice. Nat Med 7: 638-639.

25. Albertson TM, Ogawa M, Bugni JM, Hays LE, Chen Y, et al. (2009) DNA polymerase $\varepsilon$ and $\delta$ proofreading suppress discrete mutator and cancer phenotypes in mice. Proc Natl Acad Sci USA 106: 17101-17104.

26. Goldsby RE, Hays LE, Chen X, Olmsted EA, Slayton WB, et al. (2002) High incidence of epithelial cancers in mice deficient for DNA polymerase $\delta$ proofreading. Proc Natl Acad Sci USA 99: 15560-15565.

27. Wei K, Kucherlapati R, Edelmann W (2002) Mouse models for human DNA mismatch-repair gene defects. Trends Mol Med 8: 346-353.

28. Peltomäki P (2005) Lynch syndrome genes. Fam Cancer 4: 227-232.

29. Simon M, Giot L, Faye G (1991) The $3^{\prime}$ to $5^{\prime}$ exonuclease activity located in the DNA polymerase $\delta$ subunit of Saccharomyces cerevisiae is required for accurate replication. EMBO J 10: 2165-2170.

30. Morrison A, Bell JB, Kunkel TA, Sugino A (1991) Eukaryotic DNA polymerase amino acid sequence required for $3^{\prime} \rightarrow 5^{\prime}$ exonuclease activity. Proc Natl Acad Sci USA 88: 9473-9477.

31. Williamson MS, Game JC, Fogel S (1985) Meiotic gene conversion mutants in Saccharomyces cerevisiae. I. Isolation and characterization of pms1-1 and pms1-2. Genetics 110: 609-646.

32. Reenan RA, Kolodner RD (1992) Characterization of insertion mutations in the Saccharomyces cerevisiae MSH1 and MSH2 genes: evidence for separate mitochondrial and nuclear functions. Genetics 132: 975-985.

33. Prolla TA, Christie DM, Liskay RM (1994) Dual requirement in yeast DNA mismatch repair for $M L H 1$ and $P M S 1$, two homologs of the bacterial mutL gene. Mol Cell Biol 14: 407-415.

34. Strand M, Prolla TA, Liskay RM, Petes TD (1993) Destabilization of tracts of simple repetitive DNA in yeast by mutations affecting DNA mismatch repair. Nature 365: 274-276.

35. Desai MM, Fisher DS, Murray AW (2007) The speed of evolution and maintenance of variation in asexual populations. Curr Biol 17: 385-394. 
36. Thompson DA, Desai MM, Murray AW (2006) Ploidy controls the success of mutators and nature of mutations during budding yeast evolution. Curr Biol 16: $1581-1590$.

37. Wloch DM, Szafraniec K, Borts RH, Korona R (2001) Direct estimate of the mutation rate and the distribution of fitness effects in the yeast Saccharomyces cerevisiae. Genetics 159: 441-452.

38. Zeyl C, de Visser JAGM (2001) Estimates of the rate and distribution of fitness effects of spontaneous mutation in Saccharomyces cerevisiae. Genetics 157: 53-61.

39. Zeyl C, Mizesko M, de Visser JAGM (2001) Mutational meltdown in laboratory yeast populations. Evolution 55: 909-917.

40. Morrison A, Johnson AL, Johnston LH, Sugino A (1993) Pathway correcting DNA replication errors in Saccharomyces cerevisiae. EMBO J 12: 1467-1473.

41. Tran HT, Gordenin DA, Resnick MA (1999) The $3^{\prime} \rightarrow 5^{\prime}$ exonucleases of DNA polymerases $\delta$ and $\varepsilon$ and the $5^{\prime} \rightarrow 3^{\prime}$ exonuclease Exol have major roles in postreplication mutation avoidance in Saccharomyces cerevisiae. Mol Cell Biol 19: 2000-2007.

42. Greene CN, Jinks-Robertson S (2001) Spontaneous frameshift mutations in Saccharomyces cerevisiae: accumulation during DNA replication and removal by proofreading and mismatch repair activities. Genetics 159: 65-75.

43. Boeke JD, LaCroute F, Fink GR (1984) A positive selection for mutants lacking orotidine-5'-phosphate decarboxylase activity in yeast: 5-fluoro-orotic acid resistance. Mol Gen Genet 197: 345-346.

44. Bernad A, Blanco L, Lazaro JM, Martin G, Salas M (1989) A conserved 3' $\rightarrow 5^{\prime}$ exonuclease active site in prokaryotic and eukaryotic DNA polymerases. Cell 59: 219-228.

45. Shevelev IV, Hübscher U (2002) The $3^{\prime}-5^{\prime}$ exonucleases. Nat Rev Mol Cell Biol 3: 364-376.

46. Morrison A, Sugino A (1994) The $3^{\prime} \rightarrow 5^{\prime}$ exonucleases of both DNA polymerases $\delta$ and $\varepsilon$ participate in correcting errors of DNA replication in Saccharomyces cerevisiae. Mol Gen Genet 242: 289-296.

47. Marsischky GT, Filosi N, Kane MF, Kolodner R (1996) Redundancy of Saccharomyces cerevisiae MSH3 and MSH6 in MSH2-dependent mismatch repair. Genes Dev 10: 407-420.

48. Johnson RE, Kovvali GK, Prakash L, Prakash S (1996) Requirement of the yeast $\mathrm{MSH} 3$ and $\mathrm{MSH} 6$ genes for $\mathrm{MSH}$ 2-dependent genomic stability. J Biol Chem 271: 7285-7288.

49. Alani E (1996) The Saccharomyces cerevisiae Msh2 and Msh6 proteins form a complex that specifically binds to duplex oligonucleotides containing mismatched DNA base pairs. Mol Cell Biol 16: 5604-5615.

50. Sokolsky T, Alani E (2000) EXO1 and MSH6 are high-copy suppressors of conditional mutations in the MSH2 mismatch repair gene of Saccharomyces cerevisiae. Genetics 155: 589-599.

51. Hawk JD, Stefanovic L, Boyer JC, Petes TD, Farber RA (2005) Variation in efficiency of DNA mismatch repair at different sites in the yeast genome. Proc Natl Acad Sci USA 102: 8639-8643.

52. Jin YH, Garg P, Stith CM, Al-Refai H, Sterling JF, et al. (2005) The multiple biological roles of the $3^{\prime} \rightarrow 5^{\prime}$ exonuclease of Saccharomyces cerevisiae DNA polymerase $\delta$ require switching between the polymerase and exonuclease domains. Mol Cell Biol 25: 461-471.

53. Schaaper RM (1993) Base selection, proofreading, and mismatch repair during DNA replication in Escherichia coli. J Biol Chem 268: 23762-23765.

54. Pavlov YI, Shcherbakova PV, Rogozin IB (2006) Roles of DNA polymerases in replication, repair, and recombination in eukaryotes. Int Rev Cytol 255: 41-132.

55. Giaever G, Chu AM, Ni L, Connelly C, Riles L, et al. (2002) Functional profiling of the Saccharomyces cerevisiae genome. Nature 418: 387-391.

56. Winzeler EA, Shoemaker DD, Astromoff A, Liang H, Anderson K, et al. (1999) Functional characterization of the $S$. cerevisiae genome by gene deletion and parallel analysis. Science 285: 901-906.

57. Goodman MF, Creighton S, Bloom LB, Petruska J (1993) Biochemical basis of DNA replication fidelity. Crit Rev Biochem Mol Biol 28: 83-126.

58. Datta A, Schmeits JL, Amin NS, Lau PJ, Myung K, et al. (2000) Checkpointdependent activation of mutagenic repair in Saccharomyces cerevisiae pol3-01 mutants. Mol Cell 6: 593-603.

59. Yu L, Pena Castillo L, Mnaimneh S, Hughes TR, Brown GW (2006) A survey of essential gene function in the yeast cell division cycle. Mol Biol Cell 17: $4736-4747$.

60. Ooi SL, Pan X, Peyser BD, Ye P, Meluh PB, et al. (2006) Global syntheticlethality analysis and yeast functional profiling. Trends Genet 22: 56-63.

61. Boone C, Bussey H, Andrews BJ (2007) Exploring genetic interactions and networks with yeast. Nat Rev Genet 8: 437-449.

62. Fijalkowska IJ, Schaaper RM (1996) Mutants in the Exo I motif of Escherichia coli dnaQ: defective proofreading and inviability due to error catastrophe. Proc Natl Acad Sci USA 93: 2856-2861.

63. Sliwa P, Kluz J, Korona R (2004) Mutational load and the transition between diploidy and haploidy in experimental populations of the yeast Saccharomyces cerevisiae. Genetica 121: 285-293.

64. Delneri D, Hoyle DC, Gkargkas K, Cross EJM, Rash B, et al. (2008) Identification and characterization of high-flux-control genes of yeast through competition analyses in continuous cultures. Nat Genet 40: 113-117.

65. Daee DL, Mertz TM, Shcherbakova PV (2010) A cancer-associated DNA polymerase $\delta$ variant modeled in yeast causes a catastrophic increase in genomic instability. Proc Natl Acad Sci USA 107: 157-162.
66. Treuting PM, Albertson TM, Preston BD (2010) Case series: acute tumor lysis syndrome in mutator mice with disseminated lymphoblastic lymphoma. Toxicol Pathol 38: 476-485.

67. Szafraniec K, Borts RH, Korona R (2001) Environmental stress and mutational load in diploid strains of the yeast Saccharomyces cerevisiae. Proc Natl Acad Sci USA 98: 1107-1112.

68. Hillenmeyer ME, Fung E, Wildenhain J, Pierce SE, Hoon S, et al. (2008) The chemical genomic portrait of yeast: uncovering a phenotype for all genes. Science 320: 362-365.

69. Gu Z, Steinmetz LM, Gu X, Scharfe G, Davis RW, et al. (2003) Role of duplicate genes in genetic robustness against null mutations. Nature 421: 63-66.

70. Kafri R, Levy M, Pilpel Y (2006) The regulatory utilization of genetic redundancy through responsive backup circuits. Proc Natl Acad Sci USA 103: 11653-11658.

71. Harrison R, Papp B, Pal C, Oliver SG, Delneri D (2007) Plasticity of genetic interactions in metabolic networks of yeast. Proc Natl Acad Sci USA 104: $2307-2312$.

72. Wagner A (2000) Robustness against mutations in genetic networks of yeast. Nat Genet 24: 355-361

73. Rutherford SL, Lindquist S (1998) Hsp90 as a capacitor for morphological evolution. Nature 396: 336-342.

74. Swan MK, Johnson RE, Prakash L, Prakash S, Aggarwal AK (2009) Structural basis of high-fidelity DNA synthesis by yeast DNA polymerase $\delta$. Nat Struct Mol Biol 16: 979-986.

75. Albertson TM, Preston BD (2006) DNA replication fidelity: proofreading in trans. Curr Biol 16: R209-211.

76. Trujillo KM, Sung P (2001) DNA structure-specific nuclease activities in the Saccharomyces cerevisiae Rad50·Mre11 complex. J Biol Chem 276: 35458-35464.

77. Unk I, Haracska L, Prakash S, Prakash L (2001) 3'-Phosphodiesterase and $3^{\prime} \rightarrow 5^{\prime}$ exonuclease activities of yeast Apn2 protein and requirement of these activities for repair of oxidative DNA damage. Mol Cell Biol 21: 1656-1661.

78. Bardwell AJ, Bardwell L, Tomkinson AE, Friedberg EC (1994) Specific cleavage of model recombination and repair intermediates by the yeast Rad1Rad10 DNA endonuclease. Science 265: 2082-2085.

79. Bastin-Shanower SA, Fricke WM, Mullen JR, Brill SJ (2003) The mechanism of Mus81-Mms4 cleavage site selection distinguishes it from the homologous endonuclease Rad1-Rad10. Mol Cell Biol 23: 3487-3496.

80. Boddy MN, Gaillard PH, McDonald WH, Shanahan P, Yates JR, 3rd, et al. (2001) Mus81-Emel are essential components of a Holliday junction resolvase. Cell 107: 537-548.

81. Chen XB, Melchionna R, Denis CM, Gaillard PH, Blasina A, et al. (2001) Human Mus81-associated endonuclease cleaves Holliday junctions in vitro. Mol Cell 8: 1117-1127.

82. Kaliraman V, Mullen JR, Fricke WM, Bastin-Shanower SA, Brill SJ (2001) Functional overlap between Sgs1-Top3 and the Mms4-Mus81 endonuclease. Genes Dev 15: 2730-2740.

83. Drake JW, Allen EF, Forsberg SA, Preparata RM, Greening EO (1969) Genetic control of mutation rates in bacteriophage T4. Nature 221: 1128-1132.

84. Reha-Krantz LJ (1988) Amino acid changes coded by bacteriophage T4 DNA polymerase mutator mutants. Relating structure to function. J Mol Biol 202: 711-724.

85. Reha-Krantz LJ (1995) Use of genetic analyses to probe structure, function, and dynamics of bacteriophage T4 DNA polymerase. Methods Enzymol 262: 323-331.

86. Reha-Krantz LJ, Wong C (1996) Selection of bacteriophage T4 antimutator DNA polymerases: a link between proofreading and sensitivity to phosphonoacetic acid. Mutat Res 350: 9-16.

87. Hwang YT, Zuccola HJ, Lu Q, Hwang CB (2004) A point mutation within conserved region VI of herpes simplex virus type 1 DNA polymerase confers altered drug sensitivity and enhances replication fidelity. J Virol 78: 650-657.

88. Hall JD, Coen DM, Fisher BL, Weisslitz M, Randall S, et al. (1984) Generation of genetic diversity in herpes simplex virus: an antimutator phenotype maps to the DNA polymerase locus. Virology 132: 26-37.

89. Gibbs JS, Chiou HC, Bastow KF, Cheng YC, Coen DM (1988) Identification of amino acids in herpes simplex virus DNA polymerase involved in substrate and drug recognition. Proc Natl Acad Sci USA 85: 6672-6676.

90. Loh E, Choe J, Loeb LA (2007) Highly tolerated amino acid substitutions increase the fidelity of Escherichia coli DNA polymerase I. J Biol Chem 282: 12201-12209.

91. Fijalkowska IJ, Dunn RL, Schaaper RM (1993) Mutants of Escherichia coli with increased fidelity of DNA replication. Genetics 134: 1023-1030.

92. Schaaper RM (1996) Suppressors of Escherichia coli mutT: antimutators for DNA replication errors. Mutat Res 350: 17-23.

93. Jin YH, Obert R, Burgers PM, Kunkel TA, Resnick MA, et al. (2001) The $3^{\prime} \rightarrow 5^{\prime}$ exonuclease of DNA polymerase $\delta$ can substitute for the $5^{\prime}$ flap endonuclease $\operatorname{Rad} 27 / \mathrm{Fen} 1$ in processing Okazaki fragments and preventing genome instability. Proc Natl Acad Sci USA 98: 5122-5127.

94. Garg P, Stith CM, Sabouri N, Johansson E, Burgers PM (2004) Idling by DNA polymerase $\delta$ maintains a ligatable nick during lagging-strand DNA replication. Genes Dev 18: 2764-2773. 
95. Stith CM, Sterling J, Resnick MA, Gordenin DA, Burgers PM (2008) Flexibility of eukaryotic Okazaki fragment maturation through regulated strand displacement synthesis. J Biol Chem 283: 34129-34140.

96. Pavlov YI, Maki S, Maki H, Kunkel TA (2004) Evidence for interplay among yeast replicative DNA polymerases alpha, delta and epsilon from studies of exonuclease and polymerase active site mutations. BMC Biol 2: 11.

97. Preston BD, Albertson TM, Herr AJ (2010) DNA replication fidelity and cancer. Semin Cancer Biol 20: 281-293.

98. Sherman F (2002) Getting started with yeast. In: Guthrie C, Fink GR, eds. Part B: Guide to Yeast Genetics and Molecular and Cell Biology, Volume 350 ed San Diego: Academic Press. pp 3-41.

99. Toyn JH, Gunyuzlu PL, White WH, Thompson LA, Hollis GF (2000) A counterselection for the tryptophan pathway in yeast: 5-fluoroanthranilic acid resistance. Yeast 16: 553-560.

100. Rose MD, Novick P, Thomas JH, Botstein D, Fink GR (1987) A Saccharomyces cerevisiae genomic plasmid bank based on a centromere-containing shuttle vector. Gene 60: 237-243.

101. Giot L, Simon M, Dubois C, Faye G (1995) Suppressors of thermosensitive mutations in the DNA polymerase $\delta$ gene of Saccharomyces cerevisiae. Mol Gen Genet 246: 212-222.

102. Gietz RD, Sugino A (1988) New yeast-Escherichia coli shuttle vectors constructed with in vitro mutagenized yeast genes lacking six-base pair restriction sites. Gene 74: 527-534.

103. Brachmann CB, Davies A, Cost GJ, Caputo E, Li J, et al. (1998) Designer deletion strains derived from Saccharomyces cerevisiae S288C: a useful set of strains and plasmids for PCR-mediated gene disruption and other applications. Yeast 14: 115-132.

104. Wach A, Brachat A, Pohlmann R, Philippsen P (1994) New heterologous modules for classical or PCR-based gene disruptions in Saccharomyces cerevisiae. Yeast 10: 1793-1808.

105. Venkatesan RN, Hsu JJ, Lawrence NA, Preston BD, Loeb LA (2005) Mutator phenotypes caused by substitution at a conserved motif A residue in eukaryotic DNA polymerase $\delta$. J Biol Chem 281: 4486-4494.

106. Guldener U, Heck S, Fielder T, Beinhauer J, Hegemann JH (1996) A new efficient gene disruption cassette for repeated use in budding yeast. Nucleic Acids Res 24: 2519-2524.

107. Pavlov YI, Newlon CS, Kunkel TA (2002) Yeast origins establish a strand bias for replicational mutagenesis. Mol Cell 10: 207-213.

108. Lang GI, Murray AW (2008) Estimating the per-base-pair mutation rate in the yeast Saccharomyces cerevisiae. Genetics 178: 67-82.

109. Rosche WA, Foster PL (2000) Determining mutation rates in bacterial populations. Methods 20: 4-17.

110. Zheng Q (2002) Statistical and algorithmic methods for fluctuation analysis with SALVADOR as an implementation. Math Biosci 176: 237-252.
111. Morgan C, Lewis PD (2006) iMARS--mutation analysis reporting software: an analysis of spontaneous cII mutation spectra. Mutat Res 603: 15-26.

112. Drake JW (1991) A constant rate of spontaneous mutation in DNA-based microbes. Proc Natl Acad Sci USA 88: 7160-7164.

113. Grogan DW, Carver GT, Drake JW (2001) Genetic fidelity under harsh conditions: analysis of spontaneous mutation in the thermoacidophilic archaeon Sulfolobus acidocaldarius. Proc Natl Acad Sci USA 98: 7928-7933.

114. Drake JW (2009) Avoiding dangerous missense: thermophiles display especially low mutation rates. PLoS Genet 5: e1000520. doi:10.1371/journal. pgen. 1000520

115. Croyle ML, Woo AL, Lingrel JB (1997) Extensive random mutagenesis analysis of the $\mathrm{Na} / \mathrm{K}+$-ATPase alpha subunit identifies known and previously unidentified amino acid residues that alter ouabain sensitivity--implications for ouabain binding. Eur J Biochem 248: 488-495.

116. Fallows D, Kent RB, Nelson DL, Emanuel JR, Levenson R, et al. (1987) Chromosome-mediated transfer of the murine Na,K-ATPase alpha subunit confers ouabain resistance. Mol Cell Biol 7: 2985-2987.

117. Price EM, Lingrel JB (1988) Structure-function relationships in the Na,KATPase alpha subunit: site-directed mutagenesis of glutamine-111 to arginine and asparagine-122 to aspartic acid generates a ouabain-resistant enzyme. Biochemistry 27: 8400-8408.

118. Cantley LG, Cunha MJ, Zhou XM (1994) Ouabain-resistant OR6 cells express the murine alpha 1-subunit of the Na,K-ATPase with a T797-I797 substitution. J Biol Chem 269: 15358-15361.

119. Dhillon KK, Sidorova JM, Albertson TM, Anderson JB, Ladiges WC, et al. (2010) Divergent cellular phenotypes of human and mouse cells lacking the Werner syndrome RecQ helicase. DNA Repair 9: 11-22.

120. Wang TS-F, Wong SW, Korn D (1989) Human DNA polymerase $\alpha$ : predicted functional domains and relationships with viral DNA polymerases. FASEB J 3: $14-21$.

121. Tran HT, Degtyareva NP, Gordenin DA, Resnick MA (1999) Genetic factors affecting the impact of DNA polymerase $\delta$ proofreading activity on mutation avoidance in yeast. Genetics 152: 47-59.

122. Hadjimarcou MI, Kokoska RJ, Petes TD, Reha-Krantz LJ (2001) Identification of a mutant DNA polymerase $\delta$ in Saccharomyces cerevisiae with an antimutator phenotype for frameshift mutations. Genetics 158: 177-186.

123. Tian W, Hwang YT, Lu Q Hwang CBC (2009) Finger domain mutation affects enzyme activity, DNA replication efficiency, and fidelity of an exonuclease-deficient DNA polymerase of herpes simplex virus type 1. J Virol 83: 7194-7201

124. Lynch M, Sung W, Morris K, Coffey N, Landry CR, et al. (2008) A genomewide view of the spectrum of spontaneous mutations in yeast. Proc Natl Acad Sci USA 105: 9272-9277. 